NBER WORKING PAPER SERIES

SOPHISTICATED MONETARY POLICIES

Andrew Atkeson

V. V. Chari

Patrick Kehoe

Working Paper 14883

http://www.nber.org/papers/w14883

\author{
NATIONAL BUREAU OF ECONOMIC RESEARCH \\ 1050 Massachusetts Avenue \\ Cambridge, MA 02138 \\ April 2009
}

Atkeson, Chari, and Kehoe thank the National Science Foundation for financial support and Kathleen Rolfe for excellent editorial assistance. The views expressed herein are those of the authors and not necessarily those of the Federal Reserve Bank of Minneapolis, the Federal Reserve System, or the National Bureau of Economic Research.

NBER working papers are circulated for discussion and comment purposes. They have not been peerreviewed or been subject to the review by the NBER Board of Directors that accompanies official NBER publications.

(C) 2009 by Andrew Atkeson, V. V. Chari, and Patrick Kehoe. All rights reserved. Short sections of text, not to exceed two paragraphs, may be quoted without explicit permission provided that full credit, including $(\odot$ notice, is given to the source. 
Sophisticated Monetary Policies

Andrew Atkeson, V. V. Chari, and Patrick Kehoe

NBER Working Paper No. 14883

April 2009

JEL No. E5,E52,E58,E6,E61

\begin{abstract}
In standard approaches to monetary policy, interest rate rules often lead to indeterminacy. Sophisticated policies, which depend on the history of private actions and can differ on and off the equilibrium path, can eliminate indeterminacy and uniquely implement any desired competitive equilibrium. Two types of sophisticated policies illustrate our approach. Both use interest rates as the policy instrument along the equilibrium path. But when agents deviate from that path, the regime switches, in one example to money; in the other, to a hybrid rule. Both lead to unique implementation, while pure interest rate rules do not. We argue that adherence to the Taylor principle is neither necessary nor sufficient for unique implementation with pure interest rate rules but is sufficient with hybrid rules. Our results are robust to imperfect information and may provide a rationale for empirical work on monetary policy rules and determinacy.
\end{abstract}

Andrew Atkeson

Bunche Hall 9381

Department of Economics

UCLA

Box 951477

Los Angeles, CA 90095-1477

and NBER

andy@atkeson.net

V. V. Chari

Department of Economics

University of Minnesota

1035 Heller Hall

271 - 19th Avenue South

Minneapolis, MN 55455

and NBER

chari@res.mpls.frb.fed.us
Patrick Kehoe

Research Department

Federal Reserve Bank of Minneapolis

90 Hennepin Avenue

Minneapolis, MN 55480-0291

and NBER

pkehoe@ res.mpls.frb.fed.us 
The now-classic Ramsey (1927) approach to policy analysis under commitment specifies the set of instruments available to policymakers and finds the best competitive equilibrium outcomes given those instruments. This approach has been adapted to situations with uncertainty, by Barro (1979) and Lucas and Stokey (1983), among others, by specifying the policy instruments as functions of exogenous events. ${ }^{1}$

While the Ramsey approach has been useful in identifying the best outcomes, this approach needs to be extended before it can be used to guide policy. Such an extension would describe what would happen for every history of private agent actions, government policies, and exogenous events. It would also be desirable to structure policy in such a way that policymakers can ensure that their desired outcomes occur.

Here, we provide such an extended approach. To construct it, we adapt the language of Chari and Kehoe (1990) by describing private agent actions and policies as functions of the history of private agent actions, policies, and exogenous events. The key to our approach is our requirement that for all histories, including those in which private agents deviate from the equilibrium path, the continuation outcomes constitute a competitive equilibrium. We label such policy functions sophisticated policies and the resulting equilibrium a sophisticated equilibrium. If policies can be structured so as to ensure that the desired outcomes occur, then we say that the policies uniquely implement the desired outcome.

We use this approach to analyze an important outstanding question in monetary economics: How should we design policy in order to avoid indeterminacy and to achieve unique implementation? It has been known, at least since the work of Sargent and Wallace (1975), that when interest rates are the policy instrument, many ways of specifying policy lead to indeterminate outcomes. Indeterminacy is risky because some of those outcomes can be bad, including hyperinflation. Researchers thus agree that designing policies which achieve unique implementation is desirable. Here, we demonstrate that our sophisticated policy approach does that for monetary policy.

We illustrate our approach in two standard monetary economies: a simple sticky price model with one-period price-setting and a sticky price model with staggered price-setting. For both, we show that, under sufficient conditions, any outcome of a competitive equilibrium can be uniquely implemented by appropriately constructed sophisticated policies. In particular, 
the Ramsey equilibrium can be uniquely implemented.

We construct central bank policies that uniquely implement a desired competitive equilibrium in the same basic way in both models. Along the equilibrium path, we choose the policies to be those given by the desired competitive equilibrium. We structure the policies off the equilibrium path, the reversion policies, to discourage deviations. Specifically, if the average choice of private agents deviates from that in the desired equilibrium, we choose the reversion policies so that the optimal choice, or best response, of each individual agent is different from the average choice.

When such reversion policies can be found, we say that the best responses are controllable. A sufficient condition for controllability is that policies can be found so that after a deviation the continuation equilibrium is unique and varies with policy. Variation with policy typically holds, so if policies can be found under which the continuation equilibrium is unique (somewhere), then we have unique implementation (everywhere). This sufficient condition suggests a simple way to state our message in a general way: uniqueness somewhere generates uniqueness everywhere.

One concern with our construction is that it apparently relies on the idea that the central bank perfectly observes private agents' actions and thus can detect any deviation. We show that this concern is unwarranted: our results are robust to imperfect information about private agents' actions.

The approach proposed here suggests an operational guide to policymaking. First use the Ramsey approach to determine the best competitive equilibrium, and then check whether in that situation, best responses are controllable. If they are, then sophisticated policies of the kind we have constructed can uniquely implement the Ramsey outcome. If best responses are not controllable, then the only option is to accept indeterminacy.

Our work here is related to previous work on the problem of indeterminacy in monetary economies (Wallace 1981; Obstfeld and Rogoff 1983; King 2000; Benhabib, Schmitt-Grohé, and Uribe 2001; Christiano and Rostagno 2001; and Svensson and Woodford 2005). The previous work pursues an approach different from ours (and from that in the microeconomic literature on implementation); we call it unsophisticated implementation. The basic idea of that approach is to specify policies as functions of the history and check only to see if the 
period 0 competitive equilibrium is unique.

Unsophisticated implementation has been criticized in the macroeconomic and the microeconomic literature. For example, in the macroeconomic literature, Kocherlakota and Phelan (1999), Buiter (2002), Ljungqvist and Sargent (2004), and Bassetto (2005) criticize this general idea in the context of the fiscal theory of the price level, and Cochrane (2007) criticizes it in the context of the literature on monetary policy rules. In the microeconomic literature, Jackson (2001) criticizes a related approach to implementation.

In our view, unsophisticated implementation is deficient because it does not describe how the economy will behave after a deviation by private agents from the desired outcome. This deficiency leaves open the possibility that the approach achieves implementation via nonexistence. By implementation via nonexistence, we mean an approach that specifies policy actions under which no continuation equilibrium exists after private agent deviations.

We agree with those who argue that implementation via nonexistence trivializes the implementation problem. To see why it does, consider the following policy rule: If private agents choose the desired outcome, then continue with the desired policy; if private agents deviate from the desired outcome, then forever after set government spending at a high level and taxes at zero. Clearly, under this policy rule, any deviation from the desired outcome leads to nonexistence of equilibrium, and hence, we trivially have implementation via nonexistence. We find this way of achieving implementation unpalatable.

Our approach, in contrast, insists that policies be specified so that a competitive equilibrium exists after any deviation. We achieve implementation in the traditional microeconomic sense by discouraging deviations, not by nonexistence. In our approach, policies are specified so that even if an individual agent believes that all other agents will deviate to some specific action, that individual agent finds it optimal to choose a different action. Our approach not only ensures that the continuation equilibria always exist, but also has the desirable property that the reversion policies are not extreme in any sense. That is, after deviations, our reversion policies do not threaten the private economy with dire outcomes like hyperinflation; they simply bring inflation back to the desired path.

Despite the shortcomings of the unsophisticated implementation approach, this literature has made two contributions that we find useful. One is the idea of regime-switching. 
This idea dates back to at least Wallace (1981) and has been used by Obstfeld and Rogoff (1983), Benhabib, Schmitt-Grohé, and Uribe (2001), and Christiano and Rostagno (2001). The basic idea in, say, Benhabib, Schmitt-Grohé, and Uribe (2001) is that if the economy embarks on an undesirable path, then the monetary and fiscal policy regime switches in such a way that the government's budget constraint is violated, and the undesirable path is not an equilibrium.

The other useful contribution of the literature on unsophisticated implementation is what Cochrane (2007) calls the King rule. This rule seeks to implement a desired equilibrium through an interest rate policy that makes the difference between the interest rate and its desired equilibrium level a linear function of the difference between inflation and its desired equilibrium level, with a coefficient greater than 1 . This idea dates back to at least King (2000) and has been used by Svensson and Woodford (2005). As we show here, the King rule, like other pure interest rate rules, always leads to indeterminacy in our simple model and does so for a large class of parameters in the staggered price-setting model as well.

We build on these two contributions by considering a King-money hybrid rule: when private agents deviate from the equilibrium path, the central bank uses the King rule for small deviations and switches regimes (from interest rates to money) for large deviations. Interestingly, with this rule, under our definition of equilibrium, outcomes return to the desired outcome path after deviations. In this sense, this hybrid rule achieves unique implementation after deviations, again without threatening agents with dire outcomes.

Our work here is also related to another substantial literature that aims to find monetary policy rules which eliminate indeterminacy. (See, for example, McCallum 1981 and, more recently, Woodford 2003.) The recent literature argues that to achieve a unique outcome, interest rate rules should follow the Taylor principle: interest rates relative to some exogenously specified levels should rise more than one-for-one when inflation rates rise relative to their exogenously specified levels.

We show here that adherence to the Taylor principle is neither necessary nor sufficient for unique implementation. It is not necessary because the sophisticated policy approach can uniquely implement any desired competitive equilibrium outcome, including outcomes in which along the equilibrium path the central bank follows an interest rate rule that violates 
the Taylor principle. It is not sufficient because pure interest rate rules, which use interest rates for all histories, may lead to indeterminacy even if they satisfy the Taylor principle.

Notwithstanding these considerations, our analysis of the King-money hybrid rule does lend support to the idea that adherence to the Taylor principle can sometimes help achieve unique implementation. Specifically, this is true within the class of King-money hybrid rules when the Taylor principle is used in the region where the King part of the rules applies.

We also show that a version of our model with measurement error provides a basis for empirical strategies which attempt to uncover whether in the data central bank policies ensure determinacy or allow for indeterminacy.

Here, we propose one way to eliminate indeterminacy when setting monetary policy. For some other proposed resolutions to that issue, see the work of Bassetto (2002) and Adão, Correia, and Teles (2007).

\section{A Simple Model with One-Period Price-Setting}

We begin by illustrating the basic idea of our construction of sophisticated policies using a simple model with one-period price-setting. The dynamical system associated with the competitive equilibrium of this model is straightforward, which lets us focus on the strategic aspects of sophisticated policies. With this model, we demonstrate that any desired outcome of a competitive equilibrium can be uniquely implemented by sophisticated policies with reversion to a money regime. We show that pure interest rate rules, which exclusively use interest rates as the policy instrument, cannot achieve unique implementation. Finally, we show that reversion to a hybrid rule, which uses interest rates as the policy instrument for small deviations and money for large deviations, can achieve unique implementation.

The model we analyze here is a modified version of the basic sticky price model with a New Classical Phillips curve (as in Woodford 2003, Chap. 3, Sec. 1.3). In order to make our results comparable to those in the literature, we here describe a simple, linearized version of the model. In Appendix A, we describe the general equilibrium version that, when linearized, produces the equilibrium conditions studied here. 


\section{A. The Determinants of Output and Inflation}

Consider a monetary economy populated by a large number of identical, infinitely lived consumers, a continuum of producers, and a central bank. Each producer uses labor to produce a differentiated good on the unit interval. A fraction of producers $i \in[0, \alpha)$ are flexible price producers, and a fraction $i \in[\alpha, 1]$ are sticky price producers.

In this economy, the timing within a period $t$ is as follows. At the beginning of the period, sticky price producers set their prices, after which the central bank chooses its monetary policy by setting one of its instruments, either interest rates or the quantity of money. Two shocks $\eta_{t}$ and $\nu_{t}$ are then realized. We interpret the shock $\eta_{t}$ as a flight to quality shock that affects the attractiveness of government debt relative to private claims and the shock $\nu_{t}$ as a velocity shock. At the end of the period, flexible price producers set their prices, and consumers make their decisions.

Now we develop necessary conditions for a competitive equilibrium in this economy and then, in the next subsection, formally define a competitive equilibrium. Here and throughout, we express all variables in log-deviation form. This way of expressing variables implies that none of our equations will have constant terms.

Consumer behavior in this model is summarized by an intertemporal Euler equation and a cash-in-advance constraint. We can write the linearized Euler equation as

$$
y_{t}=E_{t}\left[y_{t+1}\right]-\psi\left(i_{t}-E_{t}\left[\pi_{t+1}\right]\right)+\eta_{t},
$$

where $y_{t}$ is aggregate output, $i_{t}$ is the nominal interest rate, $\eta_{t}$ (the flight to quality shock) is an i.i.d. mean zero shock with variance $\operatorname{var}(\eta)$, and $\pi_{t+1}=p_{t+1}-p_{t}$ is the inflation rate from time period $t$ to $t+1$, where $p_{t}$ is the aggregate price level. The parameter $\psi$ determines the intertemporal elasticity, and $E_{t}$ denotes the expectations of a representative consumer given that consumer's information in period $t$, which includes the shock $\eta_{t}$.

The cash-in-advance constraint, when first-differenced, implies that the relationships among inflation $\pi_{t}$, money growth $\mu_{t}$, and output growth $y_{t}-y_{t-1}$ are given by a quantity equation of the form

$$
\pi_{t}=\mu_{t}-\left(y_{t}-y_{t-1}\right)+\nu_{t},
$$

where $\nu_{t}$ (the velocity shock) is an i.i.d. mean zero shock with variance $\operatorname{var}(\nu)$. 
We turn now to producer behavior. The optimal price set by an individual flexible price producer $i$ satisfies

$$
p_{f t}(i)=p_{t}+\gamma y_{t}
$$

where the parameter $\gamma$ is the elasticity of the equilibrium real wage with respect to output (often referred to in the literature as Taylor's $\gamma$ ). The optimal price set by a sticky price producer $i$ satisfies

$$
p_{s t}(i)=E_{t-1}\left[p_{t}+\gamma y_{t}\right]
$$

where $E_{t-1}$ denotes expectations at the beginning of period $t$ before the shocks $\eta_{t}$ and $\nu_{t}$ are realized. The aggregate price level $p_{t}$ is a linear combination of the prices $p_{f t}$ set by the flexible price producers and the prices $p_{s t}$ set by the sticky price producers and is given by

$$
p_{t}=\int_{0}^{\alpha} p_{f t}(i) d i+\int_{\alpha}^{1} p_{s t}(i) d i
$$

Using language from game theory, we can think of equations (3) and (4) as akin to the best responses of the flexible and sticky price producers given their beliefs about the aggregate price level and aggregate output.

In this model, the flexible price producers are strategically uninteresting. Their expectations about the future have no influence on their decisions; their prices are set mechanically according to the static considerations reflected in (3). Thus, in all that follows, equation (3) will hold on and off the equilibrium path, and we can think of $p_{f t}(i)$ as being residually determined by (3) and substitute out for $p_{f t}(i)$. To do so, substitute (3) into (5) and solve for $p_{t}$ to get

$$
p_{t}=\kappa y_{t}+\frac{1}{1-\alpha} \int_{\alpha}^{1} p_{s t}(i) d i
$$

where $\kappa=\alpha \gamma /(1-\alpha)$.

We follow the literature and express the sticky price producers' decisions in terms of inflation rates rather than price levels. To do so, let $x_{t}(i)=p_{s t}(i)-p_{t-1}$, and rewrite (4) as

$$
x_{t}(i)=E_{t-1}\left[\pi_{t}+\gamma y_{t}\right]
$$


For convenience, we define

$$
x_{t}=\frac{1}{1-\alpha} \int_{\alpha}^{1} x_{t}(i) d i
$$

to be the average price set by the sticky price producers relative to the aggregate price level in period $t-1$, so that we can rewrite $(7)$ as

$$
x_{t}=E_{t-1}\left[\pi_{t}+\gamma y_{t}\right]
$$

We can also rewrite (6) as

$$
\pi_{t}=\kappa y_{t}+x_{t}
$$

Consider now the setting of monetary policy in this model. When the central bank sets its policy, it has to choose to operate under either a money regime or an interest rate regime. In the money regime, the central bank's policy instrument is money growth $\mu_{t}$; it sets $\mu_{t}$, and the nominal interest rate $i_{t}$ is residually determined from the Euler equation (1) after the realization of the shock $\eta_{t}$. In the interest rate regime, the central bank's instrument is the interest rate; it sets $i_{t}$, and money growth $\mu_{t}$ is residually determined from the cash-inadvance constraint (2) after the realization of the shock $\eta_{t}$. Of course, in both regimes, the Euler equation and the cash-in-advance constraint both hold.

\section{B. Competitive Equilibrium}

Now we define a notion of competitive equilibrium for the simple model in the spirit of the work of Barro (1979) and Lucas and Stokey (1983). In this equilibrium, allocations, prices, and policies are all defined as functions of the history of exogenous events, or shocks, $s^{t}=\left(s_{0}, \ldots, s_{t}\right)$, where $s_{t}=\left(\eta_{t}, \nu_{t}\right)$.

Sticky price producer decisions and aggregate inflation and output levels can be summarized by $\left\{x_{t}\left(s^{t-1}\right), \pi_{t}\left(s^{t}\right), y_{t}\left(s^{t}\right)\right\}$. In terms of the policies, we let the regime choice as well as the policy choice within the regime be $\delta_{t}\left(s^{t-1}\right)=\left(\delta_{1 t}\left(s^{t-1}\right), \delta_{2 t}\left(s^{t-1}\right)\right)$, where the first argument $\delta_{1 t}\left(s^{t-1}\right) \in\{M, I\}$ denotes the regime choice, either money $(M)$ or the interest rate $(I)$, and the second argument denotes the policy choice within the regime, either money growth $\mu_{t}\left(s^{t-1}\right)$ or the interest rate $i_{t}\left(s^{t-1}\right)$. If the money regime is chosen in $t$, then the interest rate is determined residually at the end of that period, whereas if the interest rate 
regime is chosen in $t$, then the money growth rate is determined residually at the end of the period. Let $\left\{a_{t}\left(s^{t}\right)\right\}=\left\{x_{t}\left(s^{t-1}\right), \delta_{t}\left(s^{t-1}\right), \pi_{t}\left(s^{t}\right), y_{t}\left(s^{t}\right)\right\}$ denote a collection of allocations, prices, and policies in this competitive equilibrium.

Such a collection is a competitive equilibrium given $y_{-1}$ if it satisfies $(i)$ consumer optimality, namely, (1) and (2) for all $s^{t}$; (ii) optimality by sticky price producers, namely, (9) for all $s^{t-1}$; and (iii) optimality by flexible price producers, namely, (10) for all $s^{t}$.

We also define a continuation competitive equilibrium starting from any point in time. For example, consider the beginning of period $t$ with state variables $s^{t-1}$ and $y_{t-1}$. A collection of allocations, prices, and policies $\left\{a\left(s^{t-1}, y_{t-1}\right)\right\}_{r \geq t}=$

$$
\left\{x_{r}\left(s^{r-1} \mid s^{t-1}, y_{t-1}\right), \delta_{r}\left(s^{r-1} \mid s^{t-1}, y_{t-1}\right), \pi_{r}\left(s^{r} \mid s^{t-1}, y_{t-1}\right), y_{r}\left(s^{r} \mid s^{t-1}, y_{t-1}\right)\right\}_{r \geq t}
$$

is a continuation competitive equilibrium from $\left(s^{t-1}, y_{t-1}\right)$ if it satisfies the three conditions of a competitive equilibrium above for all periods starting from $\left(s^{t-1}, y_{t-1}\right)$. We define a continuation competitive equilibrium that starts at the end of period $t$ from $\left(s^{t-1}, y_{t-1}, x_{t}, \delta_{t}, s_{t}\right)$ in a similar way. This latter definition requires optimality by consumers and flexible price producers from $s^{t}$ onward and optimality by sticky price producers from $s^{t+1}$ onward. Obviously, a continuation competitive equilibrium starting in period 0 is simply a competitive equilibrium.

The following lemma proves that any competitive equilibrium gives rise to a New Classical Phillips curve along with some other useful properties of such an equilibrium.

Lemma 1 (New Classical Phillips Curve and Other Useful Properties) Any competitive equilibrium must satisfy

$$
\pi_{t}\left(s^{t}\right)=\kappa y_{t}\left(s^{t}\right)+E\left[\pi_{t}\left(s^{t}\right) \mid s^{t-1}\right]
$$

which is often referred to as the New Classical Phillips curve;

$$
\begin{aligned}
& E\left[y_{t}\left(s^{t}\right) \mid s^{t-1}\right]=0 \text { and } x_{t}\left(s^{t-1}\right)=E\left[\pi_{t}\left(s^{t}\right) \mid s^{t-1}\right] ; \text { and } \\
& E\left[x_{t+1}\left(s^{t}\right) \mid s^{t-1}\right]=E\left[\pi_{t+1}\left(s^{t+1}\right) \mid s^{t-1}\right]=i_{t}
\end{aligned}
$$

where $i_{t}=i_{t}\left(s^{t-1}\right)$ if the central bank uses an interest rate regime in period $t$ and $i_{t}=i_{t}\left(s^{t}\right)$ if the central bank uses a money regime in period $t$. 
Proof. To see that $E\left[y_{t}\left(s^{t}\right) \mid s^{t-1}\right]=0$, take expectations of (10) as of $s^{t-1}$ and substitute into (9). Using this result in (10), we obtain $x_{t}\left(s^{t-1}\right)=E\left[\pi_{t}\left(s^{t}\right) \mid s^{t-1}\right]$. Substituting this result into (10) yields (11). To show (13), take expectations of the Euler equation (1) with respect to $s^{t-1}$ and use $E\left[y_{t}\left(s^{t}\right) \mid s^{t-1}\right]=0$ along with the law of iterated expectations to get (13). Q.E.D.

A similar argument establishes that (11)-(13) hold for any continuation competitive equilibrium.

\section{Sophisticated Equilibrium}

We now turn to what we call sophisticated equilibrium. The definition of this concept is very similar to that for competitive equilibrium, except that here we allow allocations, prices, and policies to be functions of more than just the history of exogenous events; they are also functions of the history of both aggregate private actions and central bank policies. For sophisticated equilibrium, we require as well that for every history, the continuation of allocations, prices, and policies from that history onward constitute a continuation competitive equilibrium.

\section{Setup and Definition}

Before we turn to our formal definition, we note that our definition of sophisticated equilibrium simply specifies policy rules that the central bank must follow; it does not require that the policy rules be optimal. We specify sophisticated policies in this way in order to show that our unique implementation result does not depend on the objectives of the central bank. We think of sophisticated policies as being specified at the beginning of period 0 and of the central bank as being committed to following them.

We turn now to defining the histories that private agents and the central bank confront when they make their decisions. The public events that occur in a period are, in chronological order, $q_{t}=\left(x_{t} ; \delta_{t} ; s_{t} ; y_{t}, \pi_{t}\right)$. Letting $h_{t}$ denote the history of these events from period -1 up to and including period $t$, we have that $h_{t}=\left(h_{t-1}, q_{t}\right)$ for $t \geq 0$. The history $h_{-1}=y_{-1}$ is given. For notational convenience, we focus on perfect public equilibria in which the central bank's strategy (choice of regime and policy) is a function of only the public history. 
The public history faced by the sticky price producers at the beginning of period $t$ when they set their prices is $h_{t-1}$. A strategy for the sticky price producers is a sequence of rules $\sigma_{x}=\left\{x_{t}\left(h_{t-1}\right)\right\}$ for choosing prices for every possible public history.

The public history faced by the central bank when it chooses its regime and sets either its money growth or interest rate policy is $h_{g t}=\left(h_{t-1}, x_{t}\right)$. A strategy for the central bank $\left\{\delta_{t}\left(h_{g t}\right)\right\}$ is a sequence of rules for choosing the regime as well as the policy within the regime, either $\mu_{t}\left(h_{g t}\right)$ or $i_{t}\left(h_{g t}\right)$. Let $\sigma_{g}$ denote that policy.

At the end of period $t$, then, output and inflation are determined as functions of the relevant history $h_{y t}$ according to the rules $y_{t}\left(h_{y t}\right)$ and $\pi_{t}\left(h_{y t}\right)$. We let $\sigma_{y}=\left\{y_{t}\left(h_{y t}\right)\right\}$ and $\sigma_{\pi}=\left\{\pi_{t}\left(h_{y t}\right)\right\}$ denote the sequence of output and inflation rules.

Notice that for any history, the strategies $\sigma$ induce continuation outcomes in the natural way. For example, starting at some history $h_{t-1}$, these strategies recursively induce outcomes $\left\{a_{r}\left(s^{r} \mid h_{t-1} ; \sigma\right)\right\}$. We illustrate this recursion for period $t$. The sticky price producer's decision in $t$ is given by $x_{t}\left(i, s^{t-1} \mid h_{t-1} ; \sigma\right)=x_{t}\left(h_{t-1}\right)$, where $x_{t}\left(h_{t-1}\right)$ is obtained from $\sigma_{x}$. The central bank's decision in $t$ is given by $\delta_{t}\left(s^{t-1} \mid h_{t-1} ; \sigma\right)=\delta_{t}\left(h_{g t}\right)$, where $h_{g t}=\left(h_{t-1}, x_{t}\left(h_{t-1}\right)\right)$ and $\delta_{t}\left(h_{g t}\right)$ is obtained from $\sigma_{g}$. The consumer and flexible price producer decisions in $t$ are given by $y_{t}\left(s^{t} \mid h_{t-1} ; \sigma\right)=y_{t}\left(h_{y t}\right)$ and $\pi_{t}\left(s^{t} \mid h_{t-1} ; \sigma\right)=\pi_{t}\left(h_{y t}\right)$, where $h_{y t}=\left(h_{t-1}, x_{t}\left(h_{t-1}\right)\right.$, $\left.\delta_{t}\left(h_{t-1}, x_{t}\left(h_{t-1}\right)\right)\right)$ and $y_{t}\left(h_{y t}\right)$ and $\pi_{t}\left(h_{y t}\right)$ are obtained from $\sigma_{y}$ and $\sigma_{\pi}$. Continuing in a similar way, we can recursively define continuation outcomes for subsequent periods. We can likewise define continuation outcomes $\left\{a_{r}\left(s^{r} \mid h_{g t} ; \sigma\right)\right\}$ and $\left\{a_{r}\left(s^{r} \mid h_{y t} ; \sigma\right)\right\}$ following histories $h_{g t}$ and $h_{y t}$, respectively.

We now use these strategies and continuation outcomes to define our notion of equilibrium. A sophisticated equilibrium given the policies here is a collection of strategies $\left(\sigma_{x}, \sigma_{g}\right)$ and allocation rules $\left(\sigma_{y}, \sigma_{\pi}\right)$ such that $(i)$ given any history $h_{t-1}$, the continuation outcomes $\left\{a_{r}\left(s^{r} \mid h_{t-1} ; \sigma\right)\right\}$ induced by $\sigma$ constitute a continuation competitive equilibrium and $(i i)$ given any history $h_{y t}$, so do the continuation outcomes $\left\{a_{r}\left(s^{r} \mid h_{y t} ; \sigma\right)\right\} .^{2}$

Associated with each sophisticated equilibrium $\sigma=\left(\sigma_{g}, \sigma_{x}, \sigma_{y}, \sigma_{\pi}\right)$ are the particular stochastic processes for outcomes that occur along the equilibrium path, which we call sophisticated outcomes. These outcomes are competitive equilibrium outcomes.

We will say a policy $\sigma_{g}^{*}$ uniquely implements a desired competitive equilibrium $\left\{a_{t}^{*}\left(s^{t}\right)\right\}$ 
if the sophisticated outcome associated with any sophisticated equilibrium of the form $\left(\sigma_{g}^{*}, \sigma_{x}\right.$, $\left.\sigma_{y}, \sigma_{\pi}\right)$ coincides with the desired competitive equilibrium.

A central feature of our definition of sophisticated equilibrium is our requirement that for all histories, including deviation histories, the continuation outcomes constitute a competitive equilibrium. This requirement constitutes the most important difference between our approach and that in the literature. Technically, one way of casting the literature's approach into our language of strategies and allocation rules is to consider the following notion of equilibrium. An unsophisticated equilibrium is a strategy for the central bank $\sigma_{g}$ and allocations, policies, and prices

$$
\left\{a_{t}\left(s^{t}\right)\right\}=\left\{x_{t}\left(s^{t-1}\right), \delta_{t}\left(s^{t-1}\right), \pi_{t}\left(s^{t}\right), y_{t}\left(s^{t}\right)\right\}
$$

such that $\left\{a_{t}\left(s^{t}\right)\right\}$ is a period 0 competitive equilibrium and the policies induced by $\sigma_{g}$ from $\left\{a_{t}\left(s^{t}\right)\right\}$ coincide with $\left\{\delta_{t}\left(s^{t-1}\right)\right\}$.

In our view, unsophisticated equilibrium is a deficient guide to policy. While an unsophisticated equilibrium does tell policymakers what to do for every history, it does not specify what will happen under their policies for every history, in particular, for deviation histories. Achieving implementation using the notion of unsophisticated equilibrium is, in general, trivial. As we explained earlier, one way of achieving implementation is via nonexistence: simply specify policies so that no competitive equilibrium exists after deviation histories. We find this way of achieving implementation unpalatable.

\section{Implementation with Sophisticated Policies}

We focus on implementing competitive equilibria in which the central bank uses interest rates along the equilibrium path. This focus is motivated in part by the observation that most central banks seem to use interest rates as their policy instrument. Another motivation is that if the variance of the money shock $\nu_{t}$ is large, then all of the outcomes under the money regime are undesirable.

To set up our construction of sophisticated policies, recall that in our economy the only strategically interesting agents are the sticky price producers. Their choices must satisfy a key property, that

$$
x_{t}\left(h_{t-1}\right)=E\left[\pi_{t}\left(h_{y t}\right)+\gamma y_{t}\left(h_{y t}\right)\right],
$$


where $h_{y t}=\left(h_{t-1}, x_{t}\left(h_{t-1}\right), \delta_{t}\left(h_{t-1}, x_{t}\left(h_{t-1}\right)\right), s_{t}\right)$. Notice that $x_{t}\left(h_{t-1}\right)$ shows up on both sides of equation (14), so we require that the optimal choice $x_{t}\left(h_{t-1}\right)$ satisfy a fixed point property. To get some intuition for this property, suppose that each sticky price producer believes that all other sticky price producers will choose some value, say, $\hat{x}_{t}$. This choice, together with the central bank's strategy and the inflation and output rules, induces the outcomes $\pi_{t}\left(\hat{h}_{y t}\right)$ and $y_{t}\left(\hat{h}_{y t}\right)$, where $\hat{h}_{y t}=\left(h_{t-1}, \hat{x}_{t}, \delta_{t}\left(h_{t-1}, \hat{x}_{t}\right), s_{t}\right)$. The fixed point property requires that in order for $\hat{x}_{t}$ to be part of an equilibrium, each sticky price producer's best response must coincide with $\hat{x}_{t}$.

The basic idea behind our sophisticated policy construction is that the central bank starts by picking any desired competitive equilibrium allocations and sets its policy on the equilibrium path consistent with them. The central bank then constructs its policy off the equilibrium path so that even if an individual agent believes that all other agents will deviate to some specific action, that individual agent finds it optimal to choose a different action. In this sense, the policies are specified so that the fixed point property is satisfied at only the desired allocations.

With Reversion to a Money Regime We now show that in the simple sticky price model, any competitive equilibrium in which the central bank uses the interest rate as its instrument in all periods can be uniquely implemented with sophisticated policies which involve reversion to a money regime for one period.

To do so, we consider sophisticated policies with one-period reversion to money. Under these policies, after a deviation, the central bank switches to a money regime for one period.

More precisely, fix a desired competitive equilibrium outcome path $\left(x_{t}^{*}\left(s^{t-1}\right), \pi_{t}^{*}\left(s^{t}\right)\right.$, $\left.y_{t}^{*}\left(s^{t}\right)\right)$ together with central bank policies $i_{t}^{*}\left(s^{t-1}\right)$. Consider the following trigger-type policy: If sticky price producers choose $x_{t}$ in period $t$ to coincide with the desired outcomes $x_{t}^{*}\left(s^{t-1}\right)$, then let central bank policy in $t$ be $i_{t}^{*}\left(s^{t-1}\right)$. If not, and these producers deviate to some $\hat{x}_{t} \neq x_{t}^{*}\left(s^{t-1}\right)$, then for that period $t$, let the central bank switch to a money regime with a suitably chosen level of money growth. This level of money growth makes it not optimal for any individual sticky price-setter to cooperate with the deviation. If such a level of money growth exists, we say that best responses of the sticky price setters are controllable. The 
following lemma shows that this property holds for our model.

Lemma 2 (Controllability of Best Responses with One-Period Price-Setting) For any history $\left(h_{t-1}, \hat{x}_{t}\right)$, if the central bank chooses the money regime, then there exists a choice for money growth $\mu_{t}$ such that

$$
\hat{x}_{t} \neq E\left[\pi_{t}\left(\hat{h}_{y t}\right)+\gamma y_{t}\left(\hat{h}_{y t}\right)\right],
$$

where $h_{y t}=\left(h_{t-1}, \hat{x}_{t}, M, \mu_{t}\right)$.

Proof. Substituting (2) into (10), we have that if the central bank chooses the money regime with money growth $\mu_{t}$, then output $y_{t}$ and inflation $\pi_{t}$ are uniquely determined and given by

$$
\begin{aligned}
& y_{t}=\frac{\mu_{t}+\nu_{t}+y_{t-1}-\hat{x}_{t}}{1+\kappa} \\
& \pi_{t}=\kappa y_{t}+\hat{x}_{t} .
\end{aligned}
$$

Hence,

$$
E\left[\pi_{t}\left(\hat{h}_{y t}\right)+\gamma y_{t}\left(\hat{h}_{y t}\right)\right]=\frac{\kappa+\gamma}{1+\kappa}\left(\mu_{t}+y_{t-1}-\hat{x}_{t}\right)+\hat{x}_{t} .
$$

Clearly, then, any choice of $\mu_{t} \neq \hat{x}_{t}-y_{t-1}$ will ensure that (15) holds. Q.E.D.

We use this lemma to guide our choice of the suitable money growth rate after deviations. We choose this growth rate to generate the same expected inflation as in the original equilibrium. (Of course, we could have chosen many other values that also would discourage deviations, but we found this value to be the most intuitive. ${ }^{3}$ ) In particular, if the producers deviate to some $\hat{x}_{t} \neq x_{t}^{*}\left(s^{t-1}\right)$, then for that period $t$, let the central bank switch to a money regime with money growth set so that

$$
\left.\mu_{t}=\hat{x}_{t}-y_{t-1}+\frac{1+\kappa}{\kappa}\left[x_{t}^{*}\left(s^{t-1}\right)-\hat{x}_{t}\right)\right] .
$$

Note that $\mu_{t} \neq \hat{x}_{t}-y_{t-1}$. With such a money growth rate, expected inflation is the same in the reversion period as it would have been in the desired outcome. From Lemma 1, such a choice of $\hat{x}_{t}$ cannot be part of an equilibrium. It is also easy to see that if a deviation occurs 
in period $t$, the economy returns to the desired outcomes in period $t+1$. We have established the following proposition.

Proposition 1. Unique Implementation with Money Reversion. Any competitive equilibrium outcome in which the central bank uses interest rates as its instrument can be implemented as a unique equilibrium with sophisticated policies with one-period reversion to a money regime. Moreover, under this rule, after any deviation in period $t$, the equilibrium outcomes from period $t+1$ are the desired outcomes.

A simple way to describe our unique implementation result is that controllability of best responses under some regime guarantees unique implementation of any desired outcome. We obtain controllability by reversion to a money regime. Note that even though the money regime is not used on the equilibrium path, it is useful as an off-equilibrium commitment that helps support desired outcomes in which the central bank uses interest rates on the equilibrium path.

Notice also that the proposition implies that deviations lead to only very transitory departures from desired outcomes. In particular, we do not achieve implementation by threatening the economy with dire outcomes after deviations. (Note that the particular result, that the economy returns exactly to the desired outcomes in the period after the deviation, would not hold in a version of this model with state variables, like capital.)

So far we have focused on uniquely implementing competitive outcomes when the central bank uses interest rates as its instrument. Equations (16) and (17) imply that the equilibrium outcome under a money regime is unique, so that implementing desired outcomes is trivial when the central bank uses money as its instrument. Clearly, we can use a simple generalization of Proposition 1 to uniquely implement a competitive equilibrium in which the central bank uses interest rates in some periods and money in others.

With Pure Interest Rate Rules Here, we show that pure interest rate rules cannot achieve unique implementation.

We begin with a pure interest rate rule of the form

$$
i_{t}\left(s^{t-1}\right)=i_{t}^{*}\left(s^{t-1}\right)+\phi\left(x_{t}\left(s^{t-1}\right)-x_{t}^{*}\left(s^{t-1}\right)\right),
$$


where $i_{t}^{*}\left(s^{t-1}\right)$ and $x_{t}^{*}\left(s^{t-1}\right)$ are the interest rates and the sticky price producer choices associated with a competitive equilibrium which the central bank wants to implement uniquely. Notice that this rule specifies policy both on and off the equilibrium path. On the equilibrium path, $x_{t}\left(s^{t-1}\right)=x_{t}^{*}\left(s^{t-1}\right)$, and the rule yields $i_{t}\left(s^{t-1}\right)=i_{t}^{*}\left(s^{t-1}\right)$. Off the equilibrium path, the rule specifies how $i_{t}\left(s^{t-1}\right)$ should differ from $i_{t}^{*}\left(s^{t-1}\right)$ when $x_{t}\left(s^{t-1}\right)$ differs from $x_{t}^{*}\left(s^{t-1}\right)$. Pure interest rate rules of the form (19) have been discussed by King (2000) and Svensson and Woodford (2005).

Note from Lemma 1 that $x_{t}\left(s^{t-1}\right)=E\left[\pi_{t}\left(s^{t}\right) \mid s^{t-1}\right]$, so that the King rule can be thought of as targeting expected inflation in the sense that (19) is equivalent to

$$
i_{t}\left(s^{t-1}\right)=i_{t}^{*}\left(s^{t-1}\right)+\phi\left(E\left[\pi_{t}\left(s^{t}\right) \mid s^{t-1}\right]-E\left[\pi_{t}^{*}\left(s^{t}\right) \mid s^{t-1}\right]\right) .
$$

We now show that if the central bank follows the King rule (19), it cannot ensure unique implementation of the desired outcome. Indeed, under this rule, the economy has a continuum of equilibria. More formally:

Proposition 2. Indeterminacy of Equilibrium under the King Rule. Suppose the central bank sets interest rates $i_{t}$ according to the King rule (19). Then any of the continuum of sequences indexed by $x_{0}$ and $c$ that satisfies

$$
x_{t+1}=i_{t}+c \eta_{t}, \quad \pi_{t}=x_{t}+\kappa(1+\psi c) \eta_{t}, \text { and } y_{t}=(1+\psi c) \eta_{t}
$$

is a sophisticated outcome.

Proof. In order to verify that the multiple outcomes which satisfy (21) are part of a period 0 competitive equilibrium, we need to check that they satisfy (1), (9), and (10). That they satisfy (9) follows by taking expectations of the second and third equations in (21). Substituting for $i_{t}$ from (19) and for $x_{t+1}$ from (21) into (1), we obtain that $y_{t}=(1+\psi c) \eta_{t}$, as required by (21). Inspecting the expressions for $\pi_{t}$ and $y_{t}$ in (21) shows that they satisfy (10). Clearly, any such period 0 competitive equilibrium can be supported by a strategy by the government, $\sigma_{g}$, of the King rule form and appropriately chosen $\sigma_{x}, \sigma_{y}$, and $\sigma_{\pi}$. Q.E.D.

The intuitive idea behind the multiplicity of equilibria associated with the initial condition $x_{0}$ is that interest rate rules, including the King rule, induce nominal indeterminacy 
and do not pin down the initial price level. The intuitive idea behind the multiplicity of stochastic equilibria associated with $c \neq 0$ is that interest rates pin down only expected inflation and not the state-by-state realizations indexed by the parameter $c$.

Note that Proposition 2 implies that even if $\phi>1$, the economy has a continuum of equilibria. In that case, all but one of the equilibria has exploding inflation, in the sense that inflation eventually becomes unbounded. In the literature, researchers often restrict attention to bounded equilibria. We argue that, in this model, equilibria with exploding inflation cannot be dismissed on logical grounds. Indeed, these equilibria are perfectly reasonable because the inflation explosion is associated with a money supply explosion.

To see this association, suppose that the economy has no stochastic shocks and the desired outcomes are $\pi_{t}=0$ and $y_{t}=0$ in all periods. Then, from the cash-in-advance constraint (2), we know that the growth of the money supply is given by

$$
\mu_{t}=x_{t}=\phi^{t} x_{0}
$$

Thus, in these equilibria, inflation explodes because money growth explodes. Each equilibrium is indexed by a different initial value of the endogenous variable $x_{0}$. This endogenous variable depends solely on expectations of future policy and is not pinned down by any initial condition or transversality condition.

Such equilibria are reasonable because at the core of most monetary models is the idea that the central bank's printing of money at an ever-increasing rate leads to a hyperinflation. In these equilibria, inflation does not arise from the speculative reasons analyzed by Obstfeld and Rogoff (1983), but from the conventional money-printing reasons analyzed by Cagan (1956). In this sense, our model predicts, for perfectly standard and sensible reasons, that the economy can suffer from any one of a continuum of very undesirable paths for inflation. (Cochrane 2007 makes a similar point for a flexible price model.)

It is immediate to see that the same proposition applies to more general interest rate rules that are restricted to be the same on and off the equilibrium path. For example, Proposition 2 applies to linear feedback rules of the form

$$
i_{t}=\bar{\imath}_{t}+\sum_{s=0}^{\infty} \phi_{x s} x_{t-s}+\sum_{s=1}^{\infty} \phi_{y s} y_{t-s}+\sum_{s=1}^{\infty} \phi_{\pi s} \pi_{t-s},
$$

where the intercept term $\bar{\imath}_{t}$ can depend on the history of stochastic events. 
With Reversion to Hybrid Rules In Proposition 1 we have shown how reversion to a money regime can achieve unique implementation. In Proposition 2 and the subsequent discussion, we have shown that pure interest rate rules cannot achieve unique implementation. In our money reversion policies, even tiny deviations trigger a reversion to a money regime. A natural question then arises: Is it possible to achieve unique implementation by using hybrid rules which specify that the central bank continue to use interest rates unless the deviations are very large and then revert to a money regime for very large deviations? The answer is yes.

Consider a hybrid rule which is intended to implement a bounded competitive equilibrium $\left\{x_{t}^{*}\left(s^{t-1}\right), \pi_{t}^{*}\left(s^{t}\right), y_{t}^{*}\left(s^{t}\right)\right\}$ with an associated interest rate $i_{t}^{*}\left(s^{t-1}\right)$. Fix some $\bar{x}$ and $\underline{x}$ which satisfy $\bar{x}>\max _{t} x_{t}^{*}\left(s^{t-1}\right)$ and $\underline{x}<\min _{t} x_{t}^{*}\left(s^{t-1}\right)$. The King-money hybrid rule specifies that if $x_{t}\left(s^{t-1}\right)$ is within the interest rate interval $[\underline{x}, \bar{x}]$, then the central bank follows a King rule of the form (19). If $x_{t}\left(s^{t-1}\right)$ falls outside this interval, then the central bank reverts to a money regime and chooses the money growth rate that produces an expected inflation rate $\bar{\pi} \in[\underline{x}, \bar{x}]$. That the money growth rate can be so chosen follows from (16) and (17).

We show that an attractive feature of outcomes under this hybrid rule is that deviations from the desired path lead to only very transitory movements away from the desired path. More precisely, after any deviation in period $t$, even though inflation and output in period $t$ may differ from the desired outcomes, those in subsequent periods coincide with the desired outcomes. More formally:

Proposition 3. Unique Implementation with Hybrid Rules. The Kingmoney hybrid rule with $\phi>1$ uniquely implements any bounded competitive equilibrium. Moreover, under this rule, after any deviation in period $t$, the equilibrium outcomes from period $t+1$ are the desired outcomes.

We prove this proposition in Appendix B. Here, we sketch the argument for a deterministic version of the model. The key to the proof is a preliminary result that shows that no equilibrium outcome $x_{t}$ can be outside the interval $[\underline{x}, \bar{x}]$. To see that this is true, suppose that in some period $t, x_{t}$ is outside that interval. But when this is true, the hybrid rule specifies a money growth rate in that period which yields expected inflation inside the interval. Since 
$x_{t}$ equals expected inflation, this gives a contradiction and proves the preliminary result.

To establish uniqueness, suppose that there is some sophisticated equilibrium with $\hat{x}_{r} \neq x_{r}^{*}$ for some $r$. From the preliminary result, $\hat{x}_{r}$ must be in the interval $[\underline{x}, \bar{x}]$ where the King rule is operative. From Lemma 1, we know that in any equilibrium, $i_{t}=x_{t+1}$, so that the King rule implies that

$$
\hat{x}_{t+1}-x_{t+1}^{*}=\phi\left(\hat{x}_{t}-x_{t}^{*}\right)=\phi^{t-r}\left(\hat{x}_{r}-x_{r}^{*}\right) \text {. }
$$

Since $\phi>1$ and $x_{t}^{*}$ is bounded, eventually $\hat{x}_{t+1}$ must leave the interval $[\underline{x}, \bar{x}]$, which is a contradiction.

\section{Extension to Interest-Elastic Money Demand}

So far, to keep the exposition simple, we have assumed a cash-in-advance setup in which money demand is interest-inelastic. This feature of the model implies that if a money regime is adopted in some period $t$, then the equilibrium outcomes in that period are uniquely determined by the money growth rate in that period. This uniqueness under a money regime is what allows us to switch to a one-period money regime in order to support any desired competitive equilibrium. Now we consider economies with interest-elastic money demand. We argue that under appropriate conditions, our unique implementation result extends to such economies.

For such economies, sophisticated policies which specify reversion to money or to hybrid rules can uniquely implement any desired outcome if best responses are controllable. A sufficient condition for such controllability is that competitive equilibria are unique under a suitably chosen money regime. Here, as with inelastic money demand, the uniqueness under a money regime is what allows us to achieve unique implementation.

A sizable literature has analyzed the uniqueness of competitive equilibria under money growth policies with interest-elastic money demand. Obstfeld and Rogoff (1983) and Woodford (1994) provide sufficient conditions for this uniqueness. For example, Obstfeld and Rogoff (1983) consider a money-in-the-utility-function model with preferences of the form $u(c)+v(m)$, where $m$ is real money balances, and show that a sufficient condition for uniqueness under a money regime is for

$$
\lim _{m \rightarrow 0} m v^{\prime}(m)>0 \text {. }
$$


Obstfeld and Rogoff (1983) focus attention on flexible price models, but their results can be readily extended to our simple sticky price model. Indeed, their sufficient conditions apply unchanged to a deterministic version of that model because our model without shocks is effectively identical to a flexible price model. Hence, under appropriate sufficient conditions, our unique implementation result extends to environments with interest-elastic money demand.

\section{A Model with Staggered Price-Setting}

We turn now to a version of our simple model with staggered price-setting, often referred to as the New Keynesian model. We show that, along the lines of the argument developed above, policies with infinite reversion to either a money regime or to hybrid rules can uniquely implement any desired outcome under an interest rate regime. We also show that for a large class of economies, pure interest rate rules of the King form still lead to indeterminacy. To make our points in the simplest way, we abstract from aggregate uncertainty.

\section{A. Setup and Competitive Equilibrium}

We begin by setting up the model with staggered price-setting. The model has no aggregate uncertainty, and in it, prices are set in a staggered fashion as in the work of Calvo (1983). At the beginning of each period, a fraction $1-\alpha$ of producers are randomly chosen and allowed to reset their prices. After that, the central bank makes its decisions, and then, finally, consumers make theirs. This economy has no flexible price producers.

The linearized equations in this model are similar to those in the simple model. The Euler equation (1) and the money growth equation (2) are unchanged, except that here they have no shocks. The price set by a producer that is permitted to reset its price is given by the analog of (4), which is

$$
p_{s t}(i)=(1-\alpha \beta)\left[\sum_{r=0}^{\infty}(\alpha \beta)^{r-t}\left(\gamma y_{r}+p_{r}\right)\right],
$$

where $\beta$ is the discount factor. Here, again, Taylor's $\gamma$ is the elasticity of the equilibrium real wage with respect to output. Letting $p_{s t}$ denote the average price set by producers that are permitted to reset their prices in period $t$, we can recursively rewrite this equation as

$$
p_{s t}(i)=(1-\alpha \beta)\left(\gamma y_{t}+p_{t}\right)+\alpha \beta p_{s t+1},
$$


together with a type of transversality condition $\lim _{T \rightarrow \infty}(\alpha \beta)^{T} p_{s T}(i)=0$. The aggregate price level can then be written as

$$
p_{t}=\alpha p_{t-1}+(1-\alpha) p_{s t}
$$

To make our analysis parallel to the literature, we again translate the decisions of the sticky price producers from price levels to inflation rates. Letting $x_{t}(i)=p_{s t}(i)-p_{t-1}$ and letting $x_{t}$ denote the average of $x_{t}(i)$, with some manipulation we can rewrite $(25)$ as

$$
x_{t}=(1-\alpha \beta) \gamma y_{t}+\pi_{t}+\alpha \beta x_{t+1} \text {. }
$$

We can also rewrite $(26)$ as

$$
\pi_{t}=(1-\alpha) x_{t}
$$

and the transversality condition as $\lim _{T \rightarrow \infty}(\alpha \beta)^{T} x_{t}(i)=0$. Using $(28)$ and that $x_{t}$ is the average of $x_{t}(i)$, this restriction is equivalent to

$$
\lim _{t \rightarrow \infty}(\alpha \beta)^{t} \pi_{t}=0
$$

In addition to these conditions, we now argue that in this staggered price-setting model, a competitive equilibrium must satisfy two boundedness conditions. In general, boundedness conditions are controversial in the literature. Standard analyses of New Keynesian models impose strict boundedness conditions: in any reasonable equilibrium, both output and inflation must be bounded both above and below. Cochrane (2007) has forcefully criticized this practice, arguing that any boundedness condition must have a solid economic rationale.

Here, we provide rationales for two such conditions. We think there are solid arguments for requiring that output $y_{t}$ be bounded above, so that

$$
y_{t} \leq \bar{y} \text { for some } \bar{y}
$$

and interest rates be bounded below, so that

$$
i_{t} \geq \underline{i} \text { for some } \underline{i} \text {. }
$$

The rationale for output being bounded above is that the economy has a finite amount of labor to produce the output. The rationale for requiring that interest rates be bounded 
below comes from the restriction that the nominal interest rate must be nonnegative. ${ }^{4}$ These bounds allow for outcomes in which $y_{t}$, (the log of) output, falls without bound (so that the level of output converges to zero). The bounds also allow for outcomes in which inflation rates explode upward without limit.

Here, then, a collection of allocations, prices, and policies $a_{t}=\left\{x_{t}, \delta_{t}, \pi_{t}, y_{t}\right\}$ is a competitive equilibrium if it satisfies $(i)$ consumer optimality, namely, the deterministic versions of (1) and (2); (ii) sticky price producer optimality, (27)-(29); and (iii) the boundedness conditions, (30) and (31).

Note that any allocations that satisfy (27)-(29) also satisfy the New Keynesian Phillips curve:

$$
\pi_{t}=\kappa y_{t}+\beta \pi_{t+1},
$$

where now $\kappa=(1-\alpha)(1-\alpha \beta) \gamma / \alpha$. To see this result, use (28) to substitute for $x_{t}$ and $x_{t+1}$ in (27) and collect terms.

Here, as we did in the simple sticky price model, we define continuation competitive equilibria. For example, consider the beginning of period $t$ with a state variable $y_{t-1}$. A collection of allocations $a\left(y_{t-1}\right)=\left\{x_{r}\left(y_{t-1}\right), \delta_{r}\left(y_{t-1}\right), \pi_{r}\left(y_{t-1}\right), y_{r}\left(y_{t-1}\right)\right\}_{r \geq t}$ is a continuation competitive equilibrium with $y_{t-1}$ if it satisfies the three conditions of a competitive equilibrium above in all periods $r \geq t$. A continuation competitive equilibrium that starts at the end of period $t$ given $\left(y_{t-1}, x_{t}, \delta_{t}\right)$ is defined similarly. This definition requires optimality by consumers from $t$ onward and optimality by sticky price producers from $t+1$ onward.

\section{B. Sophisticated Equilibrium}

We turn now to sophisticated equilibrium in the staggered price-setting model.

\section{Definition}

The definition of a sophisticated equilibrium in the staggered price-setting model parallels that in the simple sticky price model. The elements needed for that definition are basically the same. The public events that occur in a period are, in chronological order,

$q_{t}=\left(x_{t} ; \delta_{t} ; y_{t}, \pi_{t}\right)$. We let $h_{t-1}$ denote the history of these events up until the beginning of period $t$. A strategy for the sticky price producers is a sequence of rules $\sigma_{x}=\left\{x_{t}\left(h_{t-1}\right)\right\}$. The 
public history faced by the central bank is $h_{g t}=\left(h_{t-1}, x_{t}\right)$, and its strategy, $\left\{\delta_{t}\left(h_{g t}\right)\right\}$. The public history faced by consumers in period $t$ is $h_{y t}=\left(h_{t-1}, x_{t}, \delta_{t}\right)$. We let $\sigma_{y}=\left\{y_{t}\left(h_{y t}\right)\right\}$ and $\sigma_{\pi}=\left\{\pi_{t}\left(h_{y t}\right)\right\}$ denote the sequences of output and inflation rules. Strategies and allocation rules induce continuation outcomes written as $\left\{a_{r}\left(h_{t-1} ; \sigma\right)\right\}_{r \geq t}$ or $\left\{a\left(h_{y t} ; \sigma\right)\right\}_{r \geq t}$ in the obvious recursive fashion.

Formally, then, a sophisticated equilibrium given the policies here is a collection of strategies $\left(\sigma_{x}, \sigma_{g}\right)$ and allocation rules $\left(\sigma_{y}, \sigma_{\pi}\right)$ such that $(i)$ given any history $h_{t-1}$, the continuation outcomes $\left\{a_{r}\left(h_{t-1} ; \sigma\right)\right\}_{r \geq t}$ induced by $\sigma$ constitute a continuation competitive equilibrium and (ii) given any history $h_{y t}$, so do the continuation outcomes $\left\{a_{r}\left(h_{y t} ; \sigma\right)\right\}_{r \geq t}$.

In this model, as in the simple sticky price model, the choices of the sticky price producers must satisfy a key fixed point property, that

$$
x_{t}\left(h_{t-1}\right)=(1-\alpha \beta) \gamma y_{t}\left(h_{y t}\right)+\pi_{t}\left(h_{y t}\right)+\alpha \beta x_{t+1}\left(h_{t}\right),
$$

where $h_{y t}=\left(h_{t-1}, x_{t}\left(h_{t-1}\right), \delta_{t}\left(h_{t-1}, x_{t}\left(h_{t-1}\right)\right)\right)$ and $h_{t}=\left(h_{y t}, \pi_{t}\left(h_{y t}\right), y_{t}\left(h_{y t}\right)\right)$. Here, as in the simple sticky price model, $x_{t}\left(h_{t-1}\right)$ shows up on both sides of the fixed point equation - on the right side, through its effect on the histories $h_{y t}$ and $h_{t}$.

\section{Implementation with Sophisticated Policies}

We now show that in the staggered price-setting model, any competitive equilibrium can be uniquely implemented with sophisticated policies.

The basic idea behind our construction is, again, that the central bank starts by picking any competitive equilibrium allocations and sets its policy on the equilibrium path consistent with those allocations. The central bank then constructs its policy off the equilibrium path so that any deviations from these allocations would never be a best response for any individual price-setter. In so doing, the constructed sophisticated policies support the chosen allocations as the unique equilibrium allocations.

We show that, under sufficient conditions, policies that specify infinite reversion to a money regime can achieve unique implementation, a pure interest rate rule of the King rule form cannot, and a King-money hybrid rule can. 
With Reversion to a Money Regime We start with sophisticated policies that specify reversion to a money regime after deviations. In our construction of sophisticated policies, we assume that the best responses of sticky price producers are controllable in that if they deviate by setting $\hat{x}_{t} \neq x_{t}^{*}$, then by infinitely reverting to the money regime, the central bank can set money growth rate policies so that the profit-maximizing value of $x_{t}(i)$ is such that $x_{t}(i) \neq \hat{x}_{t}$.

The sophisticated policy that supports a desired outcome is to follow the chosen monetary policy as long as private agents have not deviated from the desired outcome. If sticky price producers ever deviate to some choice $\hat{x}_{t}$, the central bank switches to a money regime set so that $x_{t}(i) \neq \hat{x}_{t}$. The following proposition follows immediately:

Proposition 4. Unique Implementation with Money Reversion. If the best responses of the sticky price producers are controllable, then any competitive equilibrium outcome in which the central bank uses interest rates as its instrument can be implemented as a unique equilibrium by sophisticated policies which specify reversion to a money regime.

A sufficient condition for best responses to be controllable is that in the nonlinear economy, preferences are given by $U(c, l)=\log c+b(1-l)$, where $c$ is consumption and $l$ is labor supply, so that in the linearized economy, Taylor's $\gamma$ equals one. To demonstrate controllability, suppose that after a deviation, the central bank reverts to a constant money supply $m=\log M$. With a constant money supply, it is convenient to use the original formulation of the economy with price levels rather than inflation rates. With that translation, the cash-in-advance constraint implies that $y_{r}+p_{r}=m$ for all $r$, so that (24) implies that the producer's price is simply to set

$$
p_{s t}(i)=(1-\alpha \beta)\left[\sum_{r=0}^{\infty}(\beta \alpha)^{r-t} m\right]=m .
$$

That is, if after a deviation the central bank chooses a constant level of the money supply $m$, then sticky price producers optimally choose their prices to be $m$. Clearly, (34) implies that the best responses of these producers are controllable. For example, consider a history in which price-setters in period $t$ deviate from $p_{s t}^{*}$ to $\hat{p}_{s t}$. Obviously, the central bank can choose the level of the money supply so that the optimal choice for an individual price-setter becomes $p_{s t}(i) \neq \hat{p}_{s t}$, so that $x_{t}(i)=m-p_{t-1} \neq \hat{x}_{t}$. 
With Pure Interest Rate Rules Here we ask, can King rules uniquely implement bounded competitive equilibrium? We find that for a large class of parameter values, the answer is no.

We arrive at this answer by first showing that under the King rule, the economy has a continuum of period 0 competitive equilibria. We then argue that associated with each competitive equilibrium is a sophisticated equilibrium.

Here, we write the King rule as

$$
i_{t}=i_{t}^{*}+\phi(1-\alpha)\left(x_{t}-x_{t}^{*}\right)
$$

where $i_{t}^{*}$ and $\pi_{t}^{*}$ are the interest rates and the inflation rates associated with the desired (bounded) competitive equilibrium. From (28), it follows that in all periods, inflation and the aggregate price-setting choice are mechanically linked by $\pi_{t}=(1-\alpha) x_{t}$. This mechanical link means that we can equally well think of policy as feeding back on inflation or on the price-setting choice so that (35) is equivalent to

$$
i_{t}=i_{t}^{*}+\phi\left(\pi_{t}-\pi_{t}^{*}\right)
$$

We show that the economy has a continuum of competitive equilibria by showing that there is a continuum of solutions to (1), (32), and (36) and that these solutions do not violate the transversality and boundedness conditions (29), (30), and (31).

It is convenient to express the variables as deviations from the desired equilibrium. To that end, let $\tilde{\pi}_{t}=\pi_{t}-\pi_{t}^{*}$ and $\tilde{y}_{t}=y_{t}-y_{t}^{*}$. Subtracting the equations governing $\left\{\pi_{t}^{*}, y_{t}^{*}\right\}$ from those governing $\left\{\pi_{t}, y_{t}\right\}$ gives a system governing $\left\{\tilde{\pi}_{t}, \tilde{y}_{t}\right\}$ which satisfies (1), (32), and (36). Substituting for $\tilde{\imath}_{t}$ in (1), using (36), we get that

$$
\tilde{y}_{t+1}+\psi \tilde{\pi}_{t+1}=\tilde{y}_{t}+\psi \phi \tilde{\pi}_{t}
$$

and from (32) we have that

$$
\tilde{\pi}_{t}=\kappa \tilde{y}_{t}+\beta \tilde{\pi}_{t+1}
$$

Equations (37) and (38) define a dynamical system. Letting $z_{t}=\left(\tilde{y}_{t}, \tilde{\pi}_{t}\right)^{\prime}$, with some manipulation we can stack these equations to give $z_{t+1}=A z_{t}$, where

$$
A=\left[\begin{array}{cc}
a & b \\
\frac{-\kappa}{\beta} & \frac{1}{\beta}
\end{array}\right]
$$


and where $a=1+\kappa \psi / \beta$ and $b=\psi(\phi-1 / \beta)$. This system has a continuum of solutions of the form

$$
\begin{aligned}
& \tilde{y}_{t}=\lambda_{1}^{t} \omega_{1}+\lambda_{2}^{t} \omega_{2} \text { and } \\
& \tilde{\pi}_{t}=\lambda_{1}^{t}\left(\frac{\lambda_{1}-a}{b}\right) \omega_{1}+\lambda_{2}^{t}\left(\frac{\lambda_{2}-a}{b}\right) \omega_{2}
\end{aligned}
$$

where $\lambda_{1}<\lambda_{2}$, the eigenvalues of $A$, are given by

$$
\lambda_{1}, \lambda_{2}=\frac{1}{2}\left(\frac{1+\kappa \psi}{\beta}+1\right) \pm \frac{1}{2} \sqrt{\left(\frac{1+\kappa \psi}{\beta}-1\right)^{2}-4(\phi-1) \frac{\kappa \psi}{\beta}}
$$

and $\omega_{1}=\left[\left(\frac{\lambda_{2}-a}{b}\right) \tilde{y}_{0}-\tilde{\pi}_{0}\right] / \Delta$ and $\omega_{2}=\left[\left(\frac{a-\lambda_{1}}{b}\right) \tilde{y}_{0}+\tilde{\pi}_{0}\right] / \Delta$, where $\Delta$ is the determinant of A. ${ }^{5}$ This continuum of solutions is indexed by $\tilde{y}_{0}$ and $\tilde{\pi}_{0}$.

In Appendix B, we show that for a class of economies that satisfy the restriction

$$
1-\kappa \psi<\beta \text { and } \alpha(1+\kappa \psi)<1
$$

equilibrium is indeterminate under the King rule. We can think of (41) as requiring that the period length is sufficiently short, in the sense that $\beta$ is close enough to 1 , and that the price stickiness is not too large, in the sense that $\alpha$ is sufficiently small. In Appendix B, we prove the following proposition:

Proposition 5. Indeterminacy of Equilibrium under the King Rule. Suppose that the central bank sets interest rates $i_{t}$ according to the King rule (35) with $\phi>1$ and that (41) is satisfied. Then the economy has a continuum of competitive equilibria indexed by $y_{0} \leq y_{0}^{*}$ :

$$
y_{t}=y_{t}^{*}+\lambda_{2}^{t}\left(y_{0}-y_{0}^{*}\right) \text { and } \pi_{t}=\pi_{t}^{*}+\lambda_{2}^{t} c\left(y_{0}-y_{0}^{*}\right)
$$

where $\lambda_{2}>1$ and $c=\left(\lambda_{2}-a\right) / b<0$ are constants.

It is immediate to construct a sophisticated equilibrium for each of the continuum of competitive equilibria in (42).

Notice that under the King rule, there is one equilibrium with $y_{t}=y_{t}^{*}$ and $\pi_{t}=\pi_{t}^{*}$ for all $t$, and in the rest, $y_{t}$ goes to minus infinity and $\pi_{t}$ goes to plus infinity. All of these 
equilibria satisfy the boundedness conditions (30) and (31) and, under (41), the transversality condition (29).

It turns out that if the inequality in the second part of (41) is reversed, then the set of solutions to the New Keynesian dynamical system, (1), (32), (28), and (44), have the form (42), but the transversality condition rules out all solutions except the one with $y_{t}=y_{t}^{*}$ and $\pi_{t}=\pi_{t}^{*}$ for all $t$. We find this way of ruling out solutions unappealing because it hinges critically on the idea that sticky price producers may be unable to change their prices for extremely long periods, even in the face of exploding inflation.

With Reversion to Hybrid Rules We now show that in the staggered price-setting model, as in the simple model, a King-money hybrid rule can uniquely implement any bounded competitive equilibrium.

To do so, we will assume boundedness under money, namely, that for any state variable $y_{t-1}$ there exists a money regime from period $t$ onward such that a continuation competitive equilibrium exists, and for all such equilibria, inflation in period $t, \pi_{t}$, is uniformly bounded. Here uniformly bounded means that there exist constants $\underline{\pi}$ and $\bar{\pi}$ such that for all $y_{t-1}$, $\pi_{t} \in[\underline{\pi}, \bar{\pi}]$. It is immediate that a sufficient condition for boundedness under money is that preferences in the nonlinear economy are given by $U(c, l)=\log c+b(1-l)$.

In an economy that satisfies boundedness under money, the King-money hybrid rule which implements a competitive equilibrium $\left\{x_{t}^{*}, \pi_{t}^{*}, y_{t}^{*}\right\}$ with an associated interest rate $i_{t}^{*}$ is defined as follows. Set $\bar{x}$ to be greater than both $\max _{t} x_{t}^{*}$ and $\bar{\pi}$, and set $\underline{x}$ to be lower than both $\min _{t} x_{t}^{*}$ and $\underline{\pi}$. This rule specifies that if $x_{t} \in[\underline{x}, \bar{x}]$, then the central bank follows a King rule of the form (35) with $\phi>1$. If $x_{t}$ falls outside the interval $[\underline{x}, \bar{x}]$, then the central bank reverts to a money regime forever.

Proposition 6. Unique Implementation with Hybrid Rules. Suppose the economy satisfies boundedness under money. Then the King-money hybrid rule implements any desired bounded competitive equilibrium. Moreover, under this rule, after any deviation in period $t$, the equilibrium outcomes from period $t+1$ are the desired outcomes.

The formal proof of this proposition is in Appendix B. The key idea of the proof is the 
same as in that for the proof of Proposition 3. The idea is that under the King rule, any $\hat{x}_{t}$ which does not equal $x_{t}^{*}$ leads subsequent price-setting choices to eventually leave the interval $[\underline{x}, \bar{x}]$. But given boundedness under money, price-setting choices outside of the interval $[\underline{x}, \bar{x}]$ cannot be part of an equilibrium.

Notice that here, as in the simple model, under hybrid rules, deviations lead to only very transitory departures from desired outcomes.

\section{Trembles and Imperfect Information}

We have shown that in a simple one-period price-setting model and in a staggered price-setting model, any equilibrium outcome can be implemented as a unique equilibrium with sophisticated policies. In our equilibria, deviations in private actions lead to changes in the regime. This observation leads to the question of how to construct sophisticated policies if trembles in private actions occur or if deviations in private actions can be detected only imperfectly. We show that our results are robust to these considerations.

\section{A. Trembles}

Consider first allowing for trembles in private decisions by supposing that the actual price chosen by a price-setter, $x_{t}(i)$, differs from the intended price, $\tilde{x}_{t}(i)$, by an additive error $\varepsilon_{t}(i)$, so that $x_{t}(i)=\tilde{x}_{t}(i)+\varepsilon_{t}(i)$.

Trembles are clearly a trivial consideration. If $\varepsilon_{t}(i)$ is independently distributed across agents, then it simply washes out in the aggregate; it is irrelevant. Even if $\varepsilon_{t}(i)$ is correlated across agents, say, because it has both aggregate and idiosyncratic components, our argument goes through unchanged if the central bank can observe the aggregate component, for example, with a random sample of prices.

\section{B. Imperfect Information}

Not as trivial is a situation in which the central bank has imperfect information about prices. We consider a formulation in which the central bank observes the actions of pricesetters with measurement error. Of course, if the central bank could see some other variable perfectly, such as output or interest rates on private debt, then it could infer what the private agents did. We think of this formulation as giving the central bank minimal amounts of 
information relative to what actual central banks have.

We show here that with imperfect information, we can implement outcomes which are close to the desired outcomes when the measurement error is small.

Here, the central bank observes the price-setters' choices with error, so that

$$
\hat{x}_{t}=x_{t}+\varepsilon_{t},
$$

where $\varepsilon_{t}$ is i.i.d. over time and has mean zero and bounded support $[\underline{\varepsilon}, \bar{\varepsilon}]$. Consider using the King-money hybrid rule to support some desired competitive equilibrium. Choose the interest rate interval $[\underline{x}, \bar{x}]$, so that $x_{t}^{*}+\varepsilon_{t}$ is contained in this interval for all $t$. Here, the King rule is of the form

$$
i_{t}\left(h_{g t}\right)=i_{t}^{*}+\phi(1-\alpha)\left(\hat{x}_{t}-x_{t}^{*}\right)
$$

with $\phi>1$.

In this economy with measurement error, the best response of any individual pricesetter is identical to that in the economy without measurement error. This result follows because the best response depends on only the expected values of future variables. Since the measurement error $\varepsilon_{t}$ has mean zero, these expected values are unchanged. Therefore, the unique equilibrium in this economy with measurement error has $x_{t}=x_{t}^{*}$. The realized value of output $y_{t}$, however, fluctuates around the desired value $y_{t}^{*}$. From the Euler equation, the realized value of output is given by

$$
y_{t}=y_{t}^{*}-\psi \phi(1-\alpha) \varepsilon_{t}
$$

Clearly, as the size of the measurement error $\varepsilon_{t}$ goes to zero, the outcomes converge to the desired outcomes. We have thus established a proposition:

Proposition 7. Approximate Implementation with Measurement Error. Suppose the sophisticated policy is described by a King-money hybrid rule described above. Then the economy has a unique equilibrium with $x_{t}=x_{t}^{*}$ and $y_{t}$ given by (45). As the variance of the measurement error approaches zero, the economy's outcomes converge to the desired outcomes. 
Note that although the central bank never reverts to a money regime when it is on the equilibrium path, the possibility that it will do so off the equilibrium path plays a critical role in this implementation.

\section{Implications for the Taylor Principle}

Our findings have implications for use of the Taylor principle as a device to ensure determinacy and to guide inferences from empirical investigations about whether central bank policy has led the economy into a determinate or indeterminate region. Recall that the Taylor principle is the notion that interest rates should rise more than one-for-one with inflation rates (both compared to some exogenous, possibly stochastic, levels).

In terms of determinacy, many economists have argued that central banks should adhere to the Taylor principle in order to ensure unique implementation. Our results imply that if the central bank is following a pure interest rate rule, adherence to the Taylor principle is neither necessary nor sufficient for unique implementation. If, however, the central bank is following a hybrid rule, adherence to the Taylor principle after deviations between observed outcomes and desired outcomes can help ensure unique implementation.

In terms of empirical investigations, many economists have estimated policy rules and inferred that central bank policy has led the economy to be in the determinate region if and only if these rules satisfy the Taylor principle. Our results imply that, given the set of assumptions made explicit in the literature, inferences regarding determinacy from existing estimation procedures should be treated with caution. We provide a set of assumptions under which it is possible to make inferences regarding determinacy.

\section{A. Setup}

In order to set up our discussion of the Taylor principle, we consider a popular specification of the Taylor rule of the form

$$
i_{t}=\bar{\imath}_{t}+\phi E_{t-1} \pi_{t}+b E_{t-1} y_{t}
$$

where $\bar{l}_{t}$ is an exogenously given, possibly stochastic, sequence. (See Taylor 1993 for a similar specification.) In our simple model, from (12), policies of the Taylor rule form (46) can be 
written as

$$
i_{t}=\bar{\imath}_{t}+\phi\left(x_{t}-\bar{x}_{t}\right)
$$

When the parameter $\phi>1$, such policies are said to satisfy the Taylor principle: The central bank should raise its interest rate more than one-for-one with increases in inflation. When $\phi<1$, such policies are said to violate that principle. Notice that when $\bar{t}_{t}$ and $\bar{x}_{t}$ coincide with the desired competitive equilibrium outcomes $i_{t}^{*}$ and $x_{t}^{*}$ for all periods, then the Taylor rule (47) reduces to the King rule (19).

\section{B. Implications for Determinacy}

Policies of the Taylor rule form (47) are linear feedback rules of the form (23) and lead to indeterminacy, regardless of the value of $\phi$. In this sense, if the central bank is following a pure interest rate rule, then adherence to the Taylor principle is not sufficient for unique implementation. A similar argument implies that, under (41), it is not sufficient in the staggered price-setting model either.

Clearly, under pure interest rate rules, adherence to the Taylor principle is also not necessary for unique implementation. Propositions 1 and 4 imply that, in both models, the central bank can uniquely implement any competitive equilibrium, including those that violate the Taylor principle along the equilibrium path.

In sum, if the central bank follows a pure interest rate rule, then adherence to the Taylor principle is neither necessary nor sufficient for unique implementation.

Notwithstanding these observations, as we have shown, if the central bank is following the King-money hybrid rule, then adherence to the Taylor principle ensures determinacy in both models.

\section{Implications for Estimation}

An extensive literature estimates monetary policy rules using variants of the Taylor rule form and tries to use these estimates to infer whether policy adheres to or violates the Taylor principle. Adherence to the principle is thought to imply that the economy is in the determinate region, and violation to imply that it is not. One branch of this literature argues that the undesirable inflation experiences of the 1970s in the United States occurred in part 
because monetary policy led the economy to be in the indeterminate region. (See, for example, Clarida, Galí, and Gertler 2000.) Our results imply that, given the set of assumptions made explicit in the literature, such inferences should be treated with great caution. We provide a set of assumptions under which such inferences can be made more confidently.

\section{Perfect Information}

In economies with perfect information, observations of variables along the equilibrium path shed no light on the properties of policies off that path, and it is off-equilibrium properties that govern the determinacy of equilibrium. Of course, any estimation procedure can rely only on data along the equilibrium path; it cannot uncover the properties of policies off that path. In this sense, estimation procedures in economies with perfect information cannot determine whether monetary policy is leading the economy to be in the determinate or the indeterminate region. (See Cochrane 2007 for a related point.)

To see this general point in the context of our models, suppose that along the equilibrium path, interest rates satisfy

$$
i_{t}^{*}=\bar{\imath}_{t}+\phi^{*}\left(x_{t}^{*}-\bar{x}_{t}\right)
$$

where $i_{t}^{*}$ and $x_{t}^{*}$ are the equilibrium outcomes and $\bar{\imath}_{t}$ and $\bar{x}_{t}$ are some exogenously given, possibly stochastic, sequences. This equilibrium can be supported in many ways, including reversion after deviations to a money regime or some sort of hybrid rule. Notice that in (48) the parameter $\phi^{*}$ simply describes the relation between the equilibrium outcomes $i_{t}^{*}$ and $x_{t}^{*}$ and has no connection to the behavior of policy after deviations.

Obviously, with a policy that specifies reversion to a money regime, the size of $\phi^{*}$ (whether it is smaller or larger than one) has no bearing on the determinacy of equilibrium.

That is also true with a policy that reverts to a hybrid rule after deviations, though perhaps not as obviously. Suppose that for small deviations, the hybrid rule specifies the King rule (20) with $\phi>1$. The parameter $\phi$ of the King rule has no connection to the parameter $\phi^{*}$ in (48). The parameter $\phi$ governs the behavior of policies after deviations, whereas the parameter $\phi^{*}$ simply describes a relationship that holds along the equilibrium path. Notice that while $\phi>1$ ensures determinacy, whether $\phi^{*}$ is smaller or larger than one has no bearing on determinacy. 
We interpret most of the current estimation procedures of the Taylor rule variety as estimating $\phi^{*}$, the parameter governing desired outcomes. In order to use these estimates to draw inferences about determinacy, researchers implicitly make two key assumptions: that the central bank is following a pure interest rate rule and that the parameter $\phi$ (the parameter describing off-equilibrium path behavior) is the same as $\phi^{*}$ (the parameter describing onequilibrium path behavior). As we have discussed, with perfect information, theory imposes no connection between $\phi$ and $\phi^{*}$, so the second assumption is not compelling. In any event, as we have seen in the two models we have studied, pure interest rate rules lead to indeterminacy, so that even if $\phi=\phi^{*}$, the size of $\phi$ is irrelevant for determinacy.

\section{Imperfect Information}

In economies with perfect information, we can draw a sharp distinction between behavior on and off the equilibrium path. In economies with imperfect information, such as those with measurement error, we cannot draw such a sharp distinction. Here, we spell out a set of assumptions under which inferences about determinacy can be drawn.

To develop the set of assumptions, consider our staggered price-setting economy with measurement error. In that economy, if the central bank follows the King-money hybrid rule with $\phi>1$, then the observed outcomes for $\hat{x}_{t}, i_{t}$, and $y_{t}$ are

$$
\begin{aligned}
& \hat{x}_{t}=x_{t}^{*}+\varepsilon_{t}, \\
& i_{t}=i_{t}^{*}+\phi(1-\alpha) \varepsilon_{t}, \text { and } \\
& y_{t}=y_{t}^{*}-\psi \phi(1-\alpha) \varepsilon_{t},
\end{aligned}
$$

where the desired outcomes are denoted by $x_{t}^{*}, i_{t}^{*}$, and $y_{t}^{*}$. Clearly, researchers can estimate the parameter $\phi$ using standard techniques if they know the desired outcomes $x_{t}^{*}, i_{t}^{*}$, and $y_{t}^{*}$ and that $\phi>1$. If the parameter $\phi<1$, then (49)-(51) characterize only one of the continuum of possible equilibria. In such a case, one could, using advanced techniques, parametrically characterize the class of possible equilibria and estimate the parameter $\phi$ as well as the parameters that index the continuum of equilibria. 
Even if researchers do not know the desired outcomes, they can estimate the parameter $\phi$. To do so, they can posit a model of those outcomes and then jointly estimate the parameter $\phi$ and the parameters of the posited model.

In sum, we can draw inferences regarding determinacy if we make two key assumptions and posit a model of desired outcomes. The key assumptions are that the central bank is following the King-money hybrid rule (and not just the King rule) and that the central bank observes private decisions with measurement error. To make this strategy operational, we obviously need to have an explicit model of the desired outcomes $\pi_{t}^{*}, i_{t}^{*}$, and $y_{t}^{*}$. (Note that by desired outcomes, we mean competitive equilibria of the given sticky price model, not equilibria of, say, the related flexible price model.)

\section{Conclusion}

We have here described our sophisticated policy approach and illustrated its use as an operational guide to policy which achieves unique implementation of any competitive equilibrium outcome. We have demonstrated that using a pure interest rate rule leads to indeterminacy. We have also constructed policies that involve regime switching to ensure determinacy: Use interest rates until private agents deviate, and then revert to a money regime or to a hybrid rule.

Our work implies that if a central bank follows a pure interest rate rule, adherence to the Taylor principle is neither necessary nor sufficient for unique implementation. Adherence to that principle may ensure determinacy, however, if monetary policy includes a reversion to the King-money hybrid rule after deviations.

We have argued that existing empirical procedures to draw inferences about the relationship between adherence to the Taylor principle and determinacy should be treated with

caution. We have provided a set of assumptions that can be more confidently used in applied work to draw inferences regarding the relationship between central bank policy and determinacy.

Finally, while we have here focused exclusively on monetary policy, the use of our operational guide is not necessarily limited to that application. The logic behind the construction of the guide should be applicable as well to other governmental policies - for example, to 
fiscal policy and to policy responses to financial crises - or to any application that aims to uniquely implement a desired outcome. 


\section{References}

Adão, Bernardino; Isabel Correia; and Pedro Teles, "Unique Monetary Equilibria with Interest Rate Rules," Manuscript, Bank of Portugal, 2007.

Barro, Robert J., "On the Determination of the Public Debt," Journal of Political Economy, 87 (October 1979), 940-71.

Bassetto, Marco, "A Game-Theoretic View of the Fiscal Theory of the Price Level," Econometrica, 70 (November 2002), 2167-95.

Bassetto, Marco, "Equilibrium and Government Commitment," Journal of Economic Theory, 124 (September 2005), 79-105.

Benhabib, Jess; Stephanie Schmitt-Grohé; and Martín Uribe, "Monetary Policy and Multiple Equilibria," American Economic Review, 91 (March 2001), 167-86.

Buiter, Willem H., "The Fiscal Theory of the Price Level: A Critique," Economic Journal, 112 (July 2002), 459-80.

Cagan, Phillip, "The Monetary Dynamics of Hyperinflation," in Studies in the Quantity Theory of Money, ed. Milton Friedman, 25-117, Chicago: University of Chicago Press, 1956.

Calvo, Guillermo A., "Staggered Prices in a Utility-Maximizing Framework," Journal of Monetary Economics, 12 (September 1983), 383-98.

Chari, V. V.; Lawrence J. Christiano; and Patrick J. Kehoe, "Optimality of the Friedman Rule in Economies with Distorting Taxes," Journal of Monetary Economics, 37 (April 1996), 203-23.

Chari, V. V., and Patrick J. Kehoe, "Sustainable Plans," Journal of Political Economy, 98 (August 1990), 783-802.

Christiano, Lawrence J., and Massimo Rostagno, "Money Growth Monitoring and the Taylor Rule," Working Paper 8539, National Bureau of Economic Research, 2001.

Clarida, Richard; Jordi Galí; and Mark Gertler, "Monetary Policy Rules and Macroeconomic Stability: Evidence and Some Theory," Quarterly Journal of Economics, 115 (February 2000), 147-80.

Cochrane, John H., "Inflation Determination with Taylor Rules: A Critical Review," Working Paper 13409, National Bureau of Economic Research, 2007. 
Correia, Isabel; Juan Pablo Nicolini; and Pedro Teles, "Optimal Fiscal and Monetary Policy: Equivalence Results," Journal of Political Economy, 116 (February 2008), 141-70.

Jackson, Matthew O., "A Crash Course in Implementation Theory," Social Choice and Welfare, 18 (October 2001), 655-708.

King, Robert G., "The New IS-LM Model: Language, Logic, and Limits," Federal Reserve Bank of Richmond Economic Quarterly, 86 (Summer 2000), 45-103.

Kocherlakota, Narayana, and Christopher Phelan, "Explaining the Fiscal Theory of the Price Level," Federal Reserve Bank of Minneapolis Quarterly Review, 23 (Fall 1999), 14-23.

Ljungqvist, Lars, and Thomas J. Sargent, Recursive Macroeconomic Theory, 2nd edition, Cambridge, Mass.: MIT Press, 2004.

Lucas, Robert E., Jr., "Equilibrium in a Pure Currency Economy," Economic Inquiry, 18 (April 1980), 203-20.

Lucas, Robert E., Jr., and Nancy L. Stokey, "Optimal Fiscal and Monetary Policy in an Economy without Capital," Journal of Monetary Economics, 12 (July 1983), 55-93.

McCallum, Bennett T., "Price Level Determinacy with an Interest Rate Policy Rule and Rational Expectations," Journal of Monetary Economics, 8 (November 1981), 319-29.

Obstfeld, Maurice, and Kenneth Rogoff, "Speculative Hyperinflations in Maximizing Models: Can We Rule Them Out?" Journal of Political Economy, 91 (August 1983), 675-87.

Ramsey, Frank P., "A Contribution to the Theory of Taxation," Economic Journal, 37 (March 1927), 47-61.

Sargent, Thomas J., and Neil Wallace, "Rational' Expectations, the Optimal Monetary Instrument, and the Optimal Money Supply Rule," Journal of Political Economy, 83 (April 1975), 241-54.

Schmitt-Grohé, Stephanie, and Martin Uribe, "Optimal Fiscal and Monetary Policy under Sticky Prices," Journal of Economic Theory, 114 (February 2004), 198-230.

Siu, Henry E., "Optimal Fiscal and Monetary Policy with Sticky Prices," Journal of Monetary Economics, 51 (April 2004), 575-607.

Svensson, Lars E. O., and Michael Woodford, "Implementing Optimal Policy through InflationForecast Targeting," in The Inflation Targeting Debate, ed. Ben S. Bernanke and Michael Woodford, Chicago: University of Chicago Press, 2005. 
Taylor, John B., "Discretion Versus Policy Rules in Practice," Carnegie-Rochester Conference Series on Public Policy, 39 (December 1993), 195-214.

Wallace, Neil, "A Hybrid Fiat-Commodity Monetary System," Journal of Economic Theory, 25 (December 1981), 421-30.

Woodford, Michael, "Monetary Policy and Price Level Determinacy in a Cash-in-Advance Economy," Economic Theory, 4 (May 1994), 345-80.

Woodford, Michael, Interest and Prices: Foundations of a Theory of Monetary Policy, Princeton, N.J.: Princeton University Press, 2003. 


\section{Notes}

${ }^{1}$ An extensive literature has used the Ramsey approach to discuss optimal monetary policy. See, among others, the work of Chari, Christiano, and Kehoe (1996); Schmitt-Grohé and Uribe (2004); Siu (2004); and Correia, Nicolini, and Teles (2008).

${ }^{2}$ In general, a sophisticated equilibrium would require that for every history (including histories in which the government acts, $h_{g t}$ ), the continuation outcomes from that history onward constitute a competitive equilibrium. Here, that requirement would be redundant since the conditions for a competitive equilibrium for $h_{g t}$ are the same as those for $h_{y t}$.

${ }^{3}$ We choose this part of the policy as a clear demonstration that after a deviation, the central bank is not doing anything exotic, such as producing a hyperinflation. Rather, in an intuitive sense, the central bank is simply getting the economy back on the track it had been on before the deviation threatened to shift it in another direction.

${ }^{4}$ Note that even though the real value of consumer holdings of bonds must satisfy a transversality condition, this condition does not impose any restrictions on the paths of $y_{t}$ and $\pi_{t}$. The reason is that in our nonlinear model, the government has access to lump-sum taxes, so that government debt can be arbitrarily chosen to satisfy any transversality condition.

${ }^{5}$ Here and throughout, we restrict attention to values of $\phi \in\left[0, \phi_{\max }\right]$, where $\phi_{\max }$ is the largest value of $\phi$ that yields real eigenvalues. That is, at $\phi_{\max }$, the discriminant in (40) is zero. 


\section{Appendix A: The Nonlinear Economies}

Here, we describe the nonlinear economies that, when linearized, give the equilibrium conditions described in the body of this work.

\section{A. The Simple Model with One-Period Price-Setting}

The nonlinear simple model with one-period price-setting is a monetary economy populated by a large number of identical, infinitely lived consumers, flexible price and sticky price intermediate good producers, final good producers, and a government.

In each period $t$, the economy experiences one of finitely many events $s_{t}$. We denote by $s^{t}=\left(s_{0}, \ldots, s_{t}\right)$ the history of events up through and including period $t$. The probability, as of period 0 , of any particular history $s^{t}$ is $g\left(s^{t}\right)$. The initial realization $s_{0}$ is given.

The timing within a period is as follows. At the beginning of the period, sticky price producers set their prices, and the government chooses its monetary policy, either by setting interest rates or by choosing the quantity of money. The event $s_{t}$ is then realized. At the end of the period, flexible price producers set their prices, and consumers and final good producers make their decisions. The event $s_{t}$ is associated with a flight to quality shock $\left(1-\tau\left(s^{t}\right)\right)$ that affects the attractiveness of government debt relative to private claims.

In each period $t$, the commodities in this economy are labor, a consumption good, money, and a continuum of intermediate goods indexed by $i \in[0,1]$. The technology for producing final goods from intermediate goods at history $s^{t}$ is

$$
y\left(s^{t}\right)=\left[\int y\left(i, s^{t}\right)^{\theta} d i\right]^{\frac{1}{\theta}},
$$

where $y\left(s^{t}\right)$ is the final good, $y\left(i, s^{t}\right)$ is an intermediate good of type $i$, and $\theta$ governs the elasticity of substitution between goods. The technology for producing each intermediate good $i$ is simply

$$
y\left(i, s^{t}\right)=l\left(i, s^{t}\right)
$$

where $l\left(i, s^{t}\right)$ is the input of labor.

Intermediate good producers behave as imperfect competitors. A fraction $\alpha$ of intermediate good producers have flexible prices; they set their prices in period $t$ after the realization of the shock $s_{t}$. A fraction $1-\alpha$ have sticky prices; they set their prices in period 
$t$ before the realization of the shock $s_{t}$. Let $P_{f}\left(i, s^{t}\right)$ denote the price set by a flexible price producer $i \in[0, \alpha]$ and $P_{s}\left(i, s^{t}\right)$, the price set by a sticky price producer $i \in[\alpha, 1]$.

Final good producers behave competitively. In each period $t$, they choose inputs $y\left(i, s^{t}\right)$, for all $i \in[0,1]$, and output $y\left(s^{t}\right)$ in order to maximize profits given by

$$
\max P\left(s^{t}\right) y\left(s^{t}\right)-\int_{0}^{\alpha} P_{f}\left(i, s^{t}\right) y\left(i, s^{t}\right) d i-\int_{\alpha}^{1} P_{s}\left(i, s^{t-1}\right) y\left(i, s^{t}\right) d i
$$

subject to (52); in (54), $P\left(s^{t}\right)$ is the price of the final good in period $t$. Solving the problem in (54) gives the input demand functions

$$
y^{d}\left(i, s^{t}\right)=\left[\frac{P\left(s^{t}\right)}{P(i)}\right]^{\frac{1}{1-\theta}} y\left(s^{t}\right)
$$

where $P(i)$ is the price charged by the intermediate good producer $i$. The zero profit condition implies that

$$
P\left(s^{t}\right)=\left[\int_{0}^{\alpha} P_{f}\left(i, s^{t}\right)^{\frac{\theta}{\theta-1}} d i+\int_{\alpha}^{1} P_{s}\left(i, s^{t-1}\right)^{\frac{\theta}{\theta-1}} d i\right]^{\frac{\theta-1}{\theta}} .
$$

Using (53), we can see that the problem faced by the flexible price producers is to choose $P_{1}\left(i, s^{t}\right)$ in order to maximize

$$
\left[P_{f}\left(i, s^{t-1}\right)-W\left(s^{t}\right)\right] y^{d}\left(i, s^{t}\right)
$$

subject to (55); in (57), $W\left(s^{t}\right)$ is the nominal wage rate. The resulting optimal price is given as a markup over the nominal wage rate

$$
P_{s}\left(i, s^{t}\right)=\frac{1}{\theta} W\left(s^{t}\right)
$$

The problem faced by the sticky price producers is to choose $P_{s}\left(i, s^{t-1}\right)$ in order to maximize

$$
\sum_{s^{t}} Q\left(s^{t} \mid s^{t-1}\right)\left[P_{s}\left(i, s^{t-1}\right)-W\left(s^{t}\right)\right] y^{d}\left(i, s^{t}\right)
$$

subject to (55); in (58), $Q\left(s^{t} \mid s^{t-1}\right)$ is the price of a dollar at $s^{t}$ in units of a dollar at $s^{t-1}$. The resulting optimal price for these producers is given as a markup over weighted expected marginal costs:

$$
P_{s}\left(i, s^{t-1}\right)=\frac{1}{\theta} \frac{\sum_{s^{t}} Q\left(s^{t} \mid s^{t-1}\right) P\left(s^{t}\right)^{\frac{1}{1-\theta}} W\left(s^{t}\right) y\left(s^{t}\right)}{\sum_{s^{t}} Q\left(s^{t} \mid s^{t-1}\right) P\left(s^{t}\right)^{\frac{1}{1-\theta}} y\left(s^{t}\right)} .
$$


The consumer side of the economy is a variant of the standard cash-in-advance formulation, as in the 1980 work of Lucas, with two modifications. One is that we assume that the government pays interest on wages at the private market interest rate. This modification ensures that the consumer's first-order condition for labor supply is undistorted, as in the cashless economies of Woodford (2003). Our other modification is that we allow for flight to quality shocks which affect the value of government debt relative to private debt.

Consumer preferences are given by

$$
\sum_{t=0}^{\infty} \sum_{s^{t}} \beta^{t} g\left(s^{t}\right) U\left(c\left(s^{t}\right), l\left(s^{t}\right)\right)
$$

where $c\left(s^{t}\right)$ and $l\left(s^{t}\right)$ are aggregate consumption and labor. In each period $t=0,1, \ldots$, consumers face a cash-in-advance constraint in which purchases of consumption goods are constrained by their aggregate holdings of nominal money balances $M\left(s^{t}\right)$ according to

$$
P\left(s^{t}\right) c\left(s^{t}\right)=M\left(s^{t}\right)
$$

as well as by a sequence of budget constraints

$$
M\left(s^{t}\right)+\frac{B\left(s^{t}\right)}{R\left(s^{t}\right)}=R_{p}\left(s^{t-1}\right)\left(1+\tau_{l}\right) W\left(s^{t-1}\right) l\left(s^{t-1}\right)+\left[1-\tau\left(s^{t-1}\right)\right] B\left(s^{t-1}\right)+T\left(s^{t}\right)+\Pi\left(s^{t}\right),
$$

where $B\left(s^{t}\right)$ is government debt with price $1 / R\left(s^{t}\right), R_{p}\left(s^{t}\right)$ is the rate of return on private debt, $\Pi\left(s^{t}\right)$ is the nominal profits of the intermediate good producers, $\tau_{l}$ is a subsidy to labor income, and $T\left(s^{t}\right)$ is nominal transfers and where the right side of (59) is given in period 0 . The subsidy $\tau_{l}$ is set, as is standard in the literature, to undo the inefficiency in a steady state due to monopoly power. Specifically, $1+\tau_{l}=1 / \theta$. Note that we have imposed that the cash-in-advance constraint holds with equality.

The consumer's problem is to maximize utility, subject to the cash-in-advance constraint, the budget constraint, and borrowing constraints, $B\left(s^{t+1}\right) \geq \bar{B}$, for some large negative number $\bar{B}$. For notational simplicity, we have suppressed decisions on holdings of private state-contingent debt with the price $Q\left(s^{t} \mid s^{t-1}\right)$ and private state-uncontingent debt with the private market interest rate $R_{p}\left(s^{t}\right)$. Clearly, $1 /\left[R_{p}\left(s^{t}\right)\right]=\sum_{s_{t+1}} Q\left(s^{t+1} \mid s^{t}\right)$ and

$$
Q\left(s^{t+1} \mid s^{t}\right)=\beta g\left(s^{t+1} \mid s^{t}\right) \frac{U_{c}\left(s^{t+1}\right) P\left(s^{t}\right)}{U_{c}\left(s^{t}\right) P\left(s^{t+1}\right)} .
$$


The first-order conditions for the consumer's problem imply that

$$
\begin{aligned}
& -\frac{U_{l}\left(s^{t}\right)}{U_{c}\left(s^{t}\right)}=\frac{\left(1+\tau_{l}\right) W\left(s^{t}\right)}{P\left(s^{t}\right)} \\
& \frac{1}{R\left(s^{t}\right)}=\left[1-\tau\left(s^{t}\right)\right] \sum_{s^{t+1}} \beta g\left(s^{t+1} \mid s^{t}\right) \frac{U_{c}\left(s^{t+1}\right)}{U_{c}\left(s^{t}\right)} \frac{P\left(s^{t}\right)}{P\left(s^{t+1}\right)} .
\end{aligned}
$$

If we log-linearize this economy, then we can obtain the equations in the body for the simple model.

\section{B. The Model with Staggered Price-Setting}

The nonlinear model with staggered price-setting is nearly identical to the simple model above. The main differences are that this new model has no flexible price producers, and each sticky price producer can reset prices in each period with probability $1-\alpha$.

In this model, the problem of a producer who is allowed to reset prices is to

$$
\max _{P_{s}\left(s^{t}\right)} \sum_{r=t}^{\infty} \sum_{s^{r}} \alpha^{r-t} Q\left(s^{r} \mid s^{t}\right)\left[P_{s}\left(s^{t}\right) C_{s}\left(s^{r}\right)-W\left(s^{r}\right) C_{s}\left(s^{r}\right)\right]
$$

subject to aggregate consumption of

$$
C_{s}\left(s^{t}\right)=\left(\frac{P_{s}\left(s^{t}\right)}{P\left(s^{t}\right)}\right)^{-\theta} C\left(s^{t}\right) .
$$

The first-order conditions imply that

$$
P_{s}\left(s^{t}\right)=\frac{\theta}{\theta-1} \frac{\sum_{r=t}^{\infty} \sum_{s^{r}} \alpha^{r-t} Q\left(s^{r} \mid s^{t}\right) \frac{W\left(s^{r}\right)}{P\left(s^{r}\right)}\left(\frac{1}{P\left(s^{r}\right)}\right)^{-\theta-1} C\left(s^{r}\right)}{\sum_{r=t}^{\infty} \sum_{s^{r}} \alpha^{r-t} Q\left(s^{r} \mid s^{t}\right)\left(\frac{1}{P\left(s^{r}\right)}\right)^{-\theta} C\left(s^{r}\right)} .
$$

The consumer side of this model is identical to that in the simple model. When linearized, this staggered price-setting model gives the equilibrium conditions described in the body.

\section{Appendix B: The Proofs of Propositions 3, 5, and 6}

\section{A. Proof of Proposition 3}

Given that the central bank follows the King-money hybrid rule, say, $\sigma_{g}^{*}$, we will show that there are unique strategies $\sigma_{x}, \sigma_{y}$, and $\sigma_{\pi}$ for private agents which together with $\sigma_{g}^{*}$ constitute a sophisticated equilibrium. We then show that this sophisticated equilibrium implements the desired outcomes. 
The strategies $\sigma_{x}, \sigma_{y}$, and $\sigma_{\pi}$ are as follows. The strategy $\sigma_{x}$ specifies $x_{t}\left(h_{t-1}\right)=$ $x_{t}^{*}\left(s^{t-1}\right)$ for all histories. The strategies $\sigma_{y}$ and $\sigma_{\pi}$ specify $y_{t}\left(h_{y t}\right)$ and $\pi_{t}\left(h_{y t}\right)$ that are the unique solutions to conditions defining consumer optimality, (1) and (2), that defining flexible price producer optimality, (10), and the King-money hybrid rule with $y_{t+1}\left(s^{t+1}\right)=y_{t+1}^{*}\left(s^{t+1}\right)$ and $x_{t+1}\left(s^{t+1}\right)=x_{t+1}^{*}\left(s^{t+1}\right)$. Note that the value of $x_{t}$ in the history $h_{y t}=\left(h_{t-1}, x_{t}, \delta_{t}, s_{t}\right)$ determines the regime in the current period and, hence, determines whether the Euler equation (1) or the cash-in-advance constraint (2) is used to solve for $y_{t}\left(h_{y t}\right)$ and $\pi_{t}\left(h_{y t}\right)$.

We now show that $\left(\sigma_{g}^{*}, \sigma_{x}, \sigma_{y}, \sigma_{\pi}\right)$ is a sophisticated equilibrium. Given that $\left\{x_{t}^{*}\left(s^{t-1}\right)\right.$, $\left.\pi_{t}^{*}\left(s^{t}\right), y_{t}^{*}\left(s^{t}\right)\right\}$ is a period 0 competitive equilibrium and that $x_{t}^{*}\left(s^{t-1}\right) \in[\underline{x}, \bar{x}]$, so that the central bank is following an interest rate regime, it follows that any tail of these outcomes $\left\{x_{t}^{*}\left(s^{t-1}\right), \pi_{t}^{*}\left(s^{t}\right), y_{t}^{*}\left(s^{t}\right)\right\}_{t \geq r}$ is a continuation competitive equilibrium starting in period $r$ regardless of the history $h_{r-1}$. On the equilibrium path, this claim follows immediately because the continuation of any competitive equilibrium is also a competitive equilibrium. Off the equilibrium path, for histories $h_{t-1}$, the tail is a period 0 competitive equilibrium (with periods suitably relabeled) and is therefore a continuation competitive equilibrium. A similar argument shows that the tail of the outcomes starting from the end of period $r$, namely, $\pi_{r}\left(h_{y r}\right)$ and $y_{r}\left(h_{y r}\right)$ together with the outcomes $\left\{x_{t}^{*}\left(s^{t-1}\right), \pi_{t}^{*}\left(s^{t}\right), y_{t}^{*}\left(s^{t}\right)\right\}_{t \geq r+1}$, constitutes a continuation competitive equilibrium.

Note that our construction implies that after any deviation in period $t$, the equilibrium outcomes from period $t+1$ are the desired outcomes.

We now establish uniqueness of the sophisticated equilibrium of the form $\left(\sigma_{g}^{*}, \sigma_{x}, \sigma_{y}, \sigma_{\pi}\right)$. We begin with a preliminary result that shows that for any $s^{t-1}$ in any equilibrium, $x_{t}\left(s^{t-1}\right) \in$ $[\underline{x}, \bar{x}]$. This argument is by contradiction. Suppose that at $s^{t-1}, x_{t}\left(s^{t-1}\right) \notin[\underline{x}, \bar{x}]$. Under the hybrid rule, the central bank reverts to a money regime with expected inflation equal to $\bar{\pi} \in[\underline{x}, \bar{x}]$. From Lemma $1, x_{t}\left(s^{t-1}\right)=\bar{\pi} \in[\underline{x}, \bar{x}]$, which contradicts $x_{t}\left(s^{t-1}\right) \notin[\underline{x}, \bar{x}]$. This result implies that along the equilibrium path, the central bank never reverts to money, so that interest rates are given by the King rule (19).

With this preliminary result, we establish uniqueness by another contradiction argument. Suppose that the economy has a sophisticated equilibrium in which in some history $h_{r-1}, x_{r}\left(h_{r-1}\right)=\hat{x}_{r}$, which differs from $x_{r}^{*}\left(s^{r-1}\right)$. Without loss of generality, suppose that 
$\hat{x}_{r}-x_{r}^{*}\left(s^{r-1}\right)=\varepsilon>0$. Let $\left\{\hat{x}_{t}\left(s^{t-1}\right), \hat{\pi}_{t}\left(s^{t}\right), \hat{y}_{t}\left(s^{t}\right)\right\}_{t \geq r}$ denote the associated continuation competitive equilibrium outcomes. Our preliminary result implies that the central bank follows the King rule in all periods. Let $\left\{\hat{\imath}_{t}\left(s^{t-1}\right)\right\}_{t \geq r}$ denote the associated interest rates. From (13), using the law of iterated expectations we have that

$$
E\left[i_{t}^{*}\left(s^{t-1}\right) \mid s^{r-1}\right]=E\left[x_{t+1}^{*}\left(s^{t}\right) \mid s^{r-1}\right] \text { and } E\left[\hat{\imath}_{t}\left(s^{t-1}\right) \mid s^{r-1}\right]=E\left[\hat{x}_{t+1}\left(s^{t}\right) \mid s^{r-1}\right] .
$$

Substituting (60) into the King rule (19) gives that

$$
E\left[\hat{x}_{t+1}\left(s^{t}\right)-x_{t+1}^{*}\left(s^{t}\right) \mid s^{r-1}\right]=\phi^{t-r} \varepsilon
$$

Since $\phi>1$ and $x_{t+1}^{*}\left(s^{t}\right)$ is bounded, for every $\varepsilon$ there exists some $T$ such that

$$
E\left[\hat{x}_{T+1}\left(s^{T}\right) \mid s^{T-1}\right]>\bar{x} .
$$

But this contradicts our preliminary result that $x_{t}\left(s^{t-1}\right) \leq \bar{x}$ for all $t$ and $s^{t-1}$. Q.E.D.

\section{B. Proof of Proposition 5}

Given our construction, we need only verify the transversality and boundedness conditions.

Consider first the transversality condition. From (40) it follows that the larger eigenvalue $\lambda_{2}(\phi)$ is a decreasing function of $\phi$ and that $\lambda_{2}(1)=(1+\kappa \psi) / \beta$. Under (41) it then follows that $\beta \alpha \lambda_{2}(\phi)<1$ for all $\phi \geq 1$. Hence, $\lim _{t \rightarrow \infty}(\alpha \beta)^{t} \tilde{\pi}_{t}=0$. Since $\pi_{t}^{*}$ is bounded, it follows that $\pi_{t}$ satisfies the transversality condition (29).

Consider next the boundedness conditions. We first show that $\left[\lambda_{2}(\phi)-a\right] / b<0$ for all $\phi \geq 1$. To do so, we show that $\lambda_{2}(\phi)-a$ is positive for $\phi \in[1,1 / \beta)$, zero at $\phi=1 / \beta$, and negative for $\phi \in\left(1 / \beta, \phi_{\max }\right]$. Note that from (40) we have that

$$
\lambda_{2}\left(\frac{1}{\beta}\right)=\frac{1}{2}\left(\frac{1+\kappa \psi}{\beta}+1\right)+\frac{1}{2} \sqrt{\left(\left(\frac{1}{\beta}-1\right)+\frac{\kappa \psi}{\beta}\right)^{2}-4\left(\frac{1}{\beta}-1\right) \frac{\kappa \psi}{\beta}} .
$$

Noticing that the term in the radical is a perfect square and using the first part of (41) gives that

$$
\lambda_{2}\left(\frac{1}{\beta}\right)=1+\frac{\kappa \psi}{\beta}=a .
$$


Since $\lambda_{2}(\phi)$ is decreasing, it follows that $\lambda_{2}(\phi)-a$ has the desired sign pattern. Since $b=\psi(\phi-1 / \beta)$, the numerator and the denominator of $\left[\lambda_{2}(\phi)-a\right] / b$ have opposite signs for all $\phi \geq 1$, so that $\left[\lambda_{2}(\phi)-a\right] / b$ is negative. Thus, the boundedness conditions are satisfied for all $\omega_{2} \leq 0$. In the resulting equilibria, inflation goes to plus infinity and output goes to minus infinity (so that the level of output goes to zero). Q.E.D.

\section{Proof of Proposition 6}

Let $\left\{x_{t}^{*}, \pi_{t}^{*}, y_{t}^{*}\right\}$ be the desired bounded competitive equilibrium. The strategies that implement this competitive equilibrium are as follows. The strategy $\sigma_{g}^{*}$ is the King-money hybrid rule. The strategy $\sigma_{x}$ specifies $x_{t}\left(h_{t-1}\right)=x_{t}^{*}$ for all histories. The strategies $\sigma_{y}$ and $\sigma_{\pi}$ specify $y_{t}\left(h_{y t}\right)$ and $\pi_{t}\left(h_{y t}\right)$ that are the unique solutions to the deterministic versions of the conditions defining consumer optimality, (1), (2), (28), (32), and the King-money hybrid rule with $y_{t+1}=y_{t+1}^{*}$ and $x_{t+1}=x_{t+1}^{*}$.

The proof that $\left(\sigma_{g}^{*}, \sigma_{x}, \sigma_{y}, \sigma_{\pi}\right)$ is a sophisticated equilibrium closely parallels that of Proposition 3.

We now establish uniqueness of the sophisticated equilibrium of the form $\left(\sigma_{g}^{*}, \sigma_{x}, \sigma_{y}, \sigma_{\pi}\right)$. We begin by showing that given $\sigma_{g}^{*}, x_{t}\left(h_{t-1}\right)=x_{t}^{*}$ for all histories. (Clearly, given $\sigma_{g}^{*}$ and $\sigma_{x}, \sigma_{y}$ and $\sigma_{\pi}$ are unique.) For reasons similar to those underlying the preliminary result in Proposition 3 , for any history $h_{t-1}, x_{t}\left(h_{t-1}\right)$ must be in the interval $[\underline{x}, \bar{x}]$, so that for any history interest rates are given by the King rule (44). Under an interest rate rule, the state $y_{t-1}$ is irrelevant; therefore, a continuation competitive equilibrium starting at the beginning of any period $t$ solves the same equations as a competitive equilibrium (starting from period $0)$. For notational simplicity, we focus on a competitive equilibrium starting from period 0 .

Suppose by way of contradiction that $\left\{\hat{x}_{t}, \hat{\pi}_{t}, \hat{y}_{t}\right\}$ is an equilibrium that does not coincide with $\left\{x_{t}^{*}, \pi_{t}^{*}, y_{t}^{*}\right\}$. Let $\tilde{x}_{t}=\hat{x}_{t}-x_{t}^{*}$ and use similar notation for $\tilde{\pi}_{t}$ and $\tilde{y}_{t}$. Then subtracting the equations governing the systems denoted with an asterisk from those denoted with a caret, we have a system governing $\left\{\tilde{x}_{t}, \tilde{\pi}_{t}, \tilde{y}_{t}\right\}$ which satisfies (the analogs of) (1), (32), and (35). The resulting system, given by (37) and (38), coincides with that in the proof of Proposition 5. Hence, the solution is given by (39) with eigenvalues given by (40).

It is easy to check that $\phi>1$ implies that both eigenvalues $\lambda_{1}$ and $\lambda_{2}$ are greater than 
one. Furthermore, at least one of $\left(\lambda_{1}-a\right) / b$ and $\left(\lambda_{2}-a\right) / b$ is nonzero. Since both of the eigenvalues are greater than one, (39) implies that if the two equilibria ever differ, then $\tilde{\pi}_{t}$ becomes unbounded, so that $\tilde{x}_{t}$ does as well. Since $x_{t}^{*}$ is bounded, then $\hat{x}_{t}$ must eventually leave the interval $[\underline{x}, \bar{x}]$, which cannot happen in equilibrium. So we have a contradiction.

Note that our construction implies that after any deviation in period $t$, the equilibrium outcomes from period $t+1$ are the desired outcomes. Thus, we have established the second part of the proposition. Q.E.D. 